\title{
Analytical determinations of luteolin
}

\author{
Alvaro Y. Tesio ${ }^{1}$ @ | Sebastian N. Robledo ${ }^{2}$ \\ ${ }^{1}$ Centro de Investigación y Desarrollo en Materiales Avanzados y Almacenamiento de Energía de Jujuy (CIDMEJu), Centro de Desarrollo Tecnológico \\ General Savio, Palpalá, Jujuy, Argentina \\ ${ }^{2}$ Departamento de Tecnología Química, Grupo GEANA, Instituto para el Desarrollo Agroindustrial y de la Salud (IDAS), Facultad de Ingeniería, \\ Universidad Nacional de Río Cuarto, Río Cuarto, Argentina
}

\section{Correspondence}

Alvaro Y. Tesio, Centro de Investigación y Desarrollo en Materiales Avanzados y Almacenamiento de Energía de Jujuy (CIDMEJu), Centro de Desarrollo Tecnológico General Savio, Palpalá, Jujuy, 4612, Argentina.

Email: atesio@cidmeju.unju.edu.ar

Sebastian N. Robledo, Departamento de Tecnología Química, Grupo GEANA, Instituto para el Desarrollo Agroindustrial y de la Salud (IDAS), Facultad de Ingeniería, Universidad Nacional de Río Cuarto, Agencia Postal N 3 (5800) Río Cuarto, Argentina.

Email: snrobledo@ing.unrc.edu.ar

\section{Funding information}

Agencia Nacional de Promoción Científica y Tecnológica FONCYT, Grant/Award Number: 00975-2018; Secretaría de Ciencia y Técnica (SECyT), Grant/Award Number: PPI 2020, Res.083/20;

Universidad Nacional de jujuy

\begin{abstract}
Plants, through the photosynthesis process, produce the substances necessary for all the life cycles of nature, which are called "primary metabolites." Moreover, there are some plants that synthesize, in addition to these, other substances with more specific functions, which are known as "secondary metabolites." It is inside this group that flavonoids are located, whose main function is to protect organisms from damage caused by different oxidizing agents. Luteolin (3,4,5,7-tetrahydroxy-flavone) belongs to the sub-class of flavonoids known as flavones and is one of 10,000 flavonoids currently known, being one of the most bio-active flavonoids. Its various beneficial properties for health, together with the increasing reduction in the use of synthetic antioxidants, make the study of luteolin a very active field. Within this, the quantification of this molecule has become a subject of very special interest given that it is transversal to all fields. In this review article, we aim to give the reader a broad and deep vision of this topic, focusing on the events reported in the last 5 years and covering all possible techniques related to analytical determinations. We will discuss in terms of advantages and disadvantages between techniques, selectivity, sensitivity, costs, time consumption, and reagents as well as in the complexity of operations.
\end{abstract}

\section{K E Y W O R D S}

antioxidant, chromatography, electroanalytical chemistry, flavonoid, luteolin

\footnotetext{
Abbreviations: CILE, composite-modified carbon ionic liquid electrode; COFs, core-shell magnetic covalent organic frameworks composites; CV, cyclic voltammetry; DAD, diode array detector; DPV, differential pulse voltammetry; ESI, electrospray ionization; FLD, fluorescence detection; GCE, glassy carbon electrode; GCPE, glassy carbon paste electrode; HPLC, high-performance liquid chromatography; ITO, indium tin oxide; LC, liquid chromatography; LOD, limit of detection; LOQ, limit of quantitation; LSV, linear sweep voltammetry; LUT, luteolin; MS, mass spectroscopy; NPCP, nitrogen-doped porous carbon polyhedron; PCA, principal component analysis; PGE, pencil graphite electrodes; QQQ, triple quad; QTOF, quadrupole time-of-flight; RGO, reduced graphene oxide; RSD, residual standard deviation; SWAASV, square wave anodic adsorptive stripping voltammetry; SWV, square wave voltammetry; TM, titanium mesh; UFLC, ultra-fast liquid chromatography; UPLC, ultra performance liquid chromatography; UV, ultraviolet.
} 


\section{1 | INTRODUCTION}

Flavonoids are benzo- $\gamma$-pyrone derivatives containing phenolic and pyranic rings in their molecular structures. Most of them have two benzene rings linked through a chain of three carbon atoms. Flavonoids are widely found in nature, mainly in fruits, seeds, and vegetables, as well as in diverse medicinal herb extract and pills. ${ }^{1}$

The 3',4',5,7-tetrahydroxy-flavone, usually called Luteolin (LUT) fits in to the subclass of flavonoids known as flavones and it is considered one of the most bioactive flavonoids. $^{2}$

As can be seen in Figure 1, LUT has both, resorcinol (Ring A) and a catechol (Ring B) in its chemical structure. This flavonoid is known for its beneficial effects on human health, such as cardiovascular protection, antiallergic, anticancer activities, and anti-ulcer effects, and it prevents cataracts. ${ }^{3}$ LUT also inhibits platelet aggregation by vasodilating action, ${ }^{4}$ cataract prevention, anti-platelet, and antithrombotic action ${ }^{5-8}$; and LUT could suppress the oxidative damage of DNA. ${ }^{9}$ Recent studies also show and reinforce anti-inflammatory, antioxidant, anticancer, cytoprotective, and macrophage polarization effects. ${ }^{10}$

Since the beginning of the pandemic produced by SARS-CoV-2 in these few months, about 40 articles have been published reporting the benefits for human health in relation to the use of flavonoids, and in most of them there are studies of LUT or at least some mention, turning it, once again, into one of the flavonoids with the greatest potential, in this case, related to the treatment or the prevention of COVID-19. The mentioned works range from general reviews showing the advantages in the use of several flavonoids ${ }^{11-13}$ to other works in which the focus is exclusively on LUT. $^{14}$

The major development that has propelled flavonoid research involves improvements in the analytical techniques used for their characterization. In early research, scientists relied on techniques such as thin layer chromatography (TLC) and UV/vis spectrophotometry, which lack sufficient specificity and sensitivity. As analytical techniques applicable to flavonoids have developed, progressively more information about the numbers of<smiles>O=c1cc(-c2ccc(O)c(O)c2)oc2cc(O)cc(O)c12</smiles>

FI G U RE 1 Chemical structure of luteolin compounds and their structural properties have become available, thereby supporting more detailed research in the field.

Chromatographic techniques contribute significantly in the area of natural products, especially regarding identification, separation, and characterization of bioactive compounds from plant sources. Efficient screening of the compounds of different extracts can be performed with chromatographic assays, such as high-performance liquid chromatography (HPLC) to identify different components. Through this technique, the chromatographic "fingerprint" of a plant extract can be obtained, for example, which is very convenient for identification purposes. ${ }^{15}$

On the other hand, the possibility to connect multiple detection devices to methods such as HPLC has made this technique a valuable and essential tool for the flavonoids separation, including luteolin. Ultraviolet (UV) detection is currently the technique used in HPLC, which can be used with multi-wavelengths or photo diode array (PDA). It is a conventional tool in studies associated with detection, quantification and classification of compounds. For high-throughput analysis, the development of techniques such as ultra-high-performance liquid chromatography (UHPLC) and ultra-performance liquid chromatography (UPLC), coupled to mass spectrometer (MS) have emerged as an alternative to the traditional HPLC technique. These technologies are capable of separating and identifying compounds with significant gains in resolution, sensitivity, and marked reduction in the overall analysis time. On the other hand, the capillary electrophoresis (CE) coupled to MS detection can provide structural information of analytes present in real matrixes.

On the other hand, known for its high speed, its economy of resources and its extremely low detection limits, electrochemical methods become widely applied to diverse samples, included flavonoids and of course, luteolin between them.

Likewise, searching more consolidated techniques available in a greater number of laboratories, in spite of the expensive equipment, enables the rise of techniques such as fluorescence, which provide great specificity and low detection limits but usually determine only one analyte by experience.

Finally, electrophoretic techniques, broadly distributed in biology labs, are used as purification methods of natural products. Although its main use is qualitative, it can also be found in articles in which it is used in quantitative determinations of flavonoids, among other compounds.

A critical assessment of the potential of new analytical methods for the determination, qualitative and quantitative, of LUT is crucial in analytical chemistry regardless of the specificity of the method. Usually, 

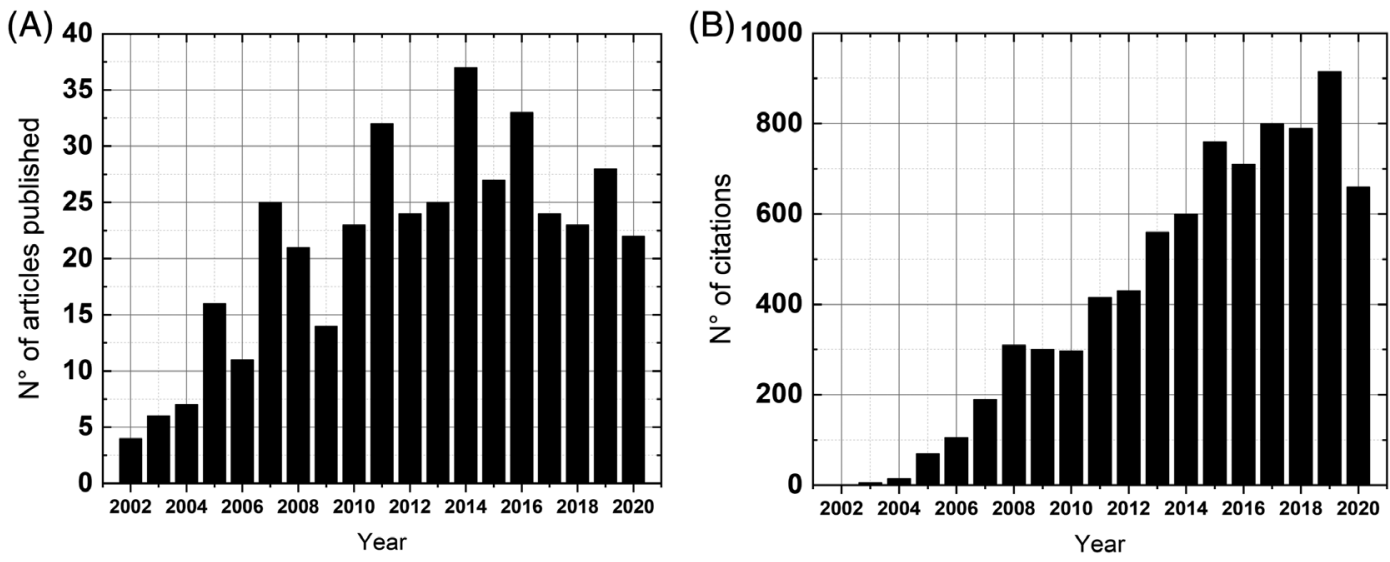

FI G U RE 2 (A) Time evolution of articles published and (B) citations of the same. Keywords used: \{"luteolin" + "chromatographic" + "determination"\} (source: Web of Science)

validation criteria are used for this purpose, including parameters such as precision, accuracy, sensitivity, recovery, and so on. Thus, the potential assessment of a method consists in separate consideration and comparison of individual parameters with commonly accepted standards, as well as between different alternative methods.

This approach has the disadvantage that it is difficult to express the analytical potential of a methodology using one unified measure, which would cover all validation criteria and allow easy overall assessment. Due to the above, conducting a comprehensive assessment of an analytical method covering all the mentioned attributes is extremely difficult without special tools aimed for this purpose. ${ }^{16}$

Likewise, we propose a critical review of the publications related to luteolin quantification methods, published in recent years, which, in our opinion, are the most relevant in their area. We did this work, emphasizing the similarities and differences between methods, as well as trying to mark advantages and disadvantages of each of them.

Finally, with the development of instruments that generate higher-order data and the in-depth study of chemometrics, chemical multiway calibration has begun to play an important role in qualitative and quantitative analysis, allowing analytes can be determined even in the presence of unexpected interferences. The possibility of detecting and modeling the presence of interferents in a sample has allowed for the development of analytical protocols, which greatly differ from classical univariate calibration methodologies. ${ }^{17}$

Thus, although to a lesser extent, the methodologies for the determination of luteolin are not beyond these proposals. For that reason, some works that tend to cover this novel field of analytics are mentioned for such aim.
Based on our experience in many determinations of toxic compounds, ${ }^{18,19}$ agri-food, ${ }^{20,21}$ and so on fundamentally through electroanalytical methods and particularly through the work carried out on various flavonoids, ${ }^{22,23}$ among them luteolin, ${ }^{24-26}$ it is that we made this review article about all the techniques developed for their determination, putting special emphasis on the most relevant ones in their fields in the last years.

\section{2 | CHROMATOGRAPHIC DETERMINATIONS}

Being one of the most widely distributed analytical technique to separate, identify, and usually quantify analytes, chromatographic techniques become the reference technique for the determination of thousands of analytes, and luteolin is not an exception.

Analyzing the production of the academic articles in the last few years through the use of the keywords \{"luteolin" + "chromatographic" + "determination"\}, we can find a big increase year by year with a big growth of its cites (Figure 2(A,B)).

Inside this topic, we will discuss some of the most relevant articles related to the field, separated by the kind of chromatographic; technically speaking, about the pressure of the chromatographic column.

\section{1 | Thin-layer chromatography}

Thin-layer chromatographic (TLC) is especially useful for the rapid screening of flavonoids in plant raw materials and extracts for food and pharma applications often focus on phenol carbonic acids and flavonoids prior to detailed analysis by instrumental techniques such as liquid 
chromatography, especially because many samples can be analyzed simultaneously. The visual detection and comparison of ratio of fronts (RF) values of applied reference substances only render limited phytochemical information.

In most cases, silica is used as stationary phase, and plates are developed with either a combination of 2-(diphenylboryoxo) ethylamine and polyethylene glycol or with $\mathrm{AlCl}_{3}$. Detection is mainly performed using UV light at $350-365$ or $250-260 \mathrm{~nm}$ or with densitometry at the same wavelengths. At present, TLC still plays an important role in flavonoid analysis.

On the other hand, other variants to TLC have also been implemented. Such as the use of thin-layer chromatographic scanning (TLCS) method for the qualitative and quantitative study of different components. TLCS not only is easy to use, economical, rapid, accurate, effective, but it also avoids the shortcomings of the traditional TLC, as well as the quantitative requirements. ${ }^{27}$

Also, TLC can be found in an automated and standardized form, that is, high-performance thin layer chromatography (HPTLC). It is widely applied for phytochemical analysis of complex samples, such as extracts and fractions from isolation processes. ${ }^{27}$

In addition, for many of these applications, the assignment or confirmation of molecular structures to TLC is important. As RF values alone are not often highly reproducible and do not allow the unequivocal assignment of a certain compound (currently established TLC-MALDI protocols involve scratching the chromatographic phase off the carrier and elution of the analyte prior to spectroscopic or mass spectrometric analysis), a matrix-assisted laser desorption/ionization time-of-flight mass spectrometry (MALDI-TOF MS) is introduced to directly read out TLC traces reproducibly while maintaining the chromatographic resolving power.

On the other hand, different classification analysis using chemometric tools, such as principal component analysis (PCA), is widely implemented in combination with different analytical techniques.

In this sense, PCA is a useful statistical technique that has found application in fields such as patterns recognition, as the case of TLC.

Patel et al. proposed HPTLC method for quantitative estimation of two compounds, one of which was luteolin, in Premna mucronata Roxb., family Verbenaceae. ${ }^{28}$ The separation was performed on silica gel 60 F254 HPTLC plates using toluene:ethyl acetate:formic acid (6:4:0.3) as mobile phase for elution of markers from extract. The determination was carried out in fluorescence mode using densitometric absorbance-reflection mode at $366 \mathrm{~nm}$ for luteolin. The calibration curve was found to be linear between 200 and $1000 \mathrm{ng} / \mathrm{band}$, the limit of detection (LOD) was found to be $42.6 \mathrm{ng} / \mathrm{band}$, while the limit of quantitation was found to be $129.08 \mathrm{ng} / \mathrm{band}$ for luteolin, respectively. The methanolic extract of Premna mucronata was found to contain $10.2 \mathrm{mg} / \mathrm{g}$ luteolin. Thus, this method is capable of quantifying and resolving luteolin and can be applicable for routine analysis of extract and plant as a whole.

Satpathy et al. developed a novel HPTLC method for the quantification of two components, including luteolin, in Hygrophila spinosa. ${ }^{29}$ The separation was carried out on HPTLC plates using the mobile phase toluene-ethyl acetate-formic acid (6.0:4.0:1.0, v/v), and detection was achieved at $349 \mathrm{~nm}$. The method was accurate in triplicate results at different standard addition levels with average recoveries of $100.01 \%$ for luteolin. The limits of detection and quantification were for luteolin 2.36 and $7.55 \mathrm{ng}$, respectively. The luteolin contents in the alcoholic extract and ethyl acetate fraction were 0.172 and $0.464 \mathrm{mg} / \mathrm{g}$, respectively. Thus, the developed method could be used for the quality control analysis and quantification of luteolin in herbal preparations containing H. spinosa.

Lan et al. determined the content of four compounds, including luteolin, in different growth stages in Artemisia rupestris L. by TLCS, which could be used as the theoretical basis for quality control and determination of harvest time. $^{30}$

Chloroform, methanol, formic acid, and water (6.35:0.63:0.17:0.07, v/v) were used as the developing solvent. The scanning wavelengths were $250 \mathrm{~nm}$ and $352 \mathrm{~nm}$. The linearity ranges of luteolin were of $0.0172-0.0976 \mu$ g. Precision analyses showed a relative standard deviation less $5.0 \%$. Their average recovery percentages were $99.9 \%$.

Kroslakova et al. studied the feasibility of direct coupling of HPTLC with MALDI-TOF MS for determination qualitative of four components, among them luteolin, on phytochemical fingerprints. All compounds studied were distinctly detected in MALDI-TOF MS, particularly luteolin that could not have been distinguished by for a simple visualization of HPTLC. ${ }^{31}$

Thus, HPTLC-MALDI-TOF MS was successfully applied to the analysis of flavonoids in complex phytochemical mixtures. The combination of the two techniques had created a helpful tool for combating difficulties occurring during analysis associated with either HPTLC (co-elution) or MALDI MS (fragmentation) when used alone.

Hawryl et al. studied seven different Scutellaria species using TLC combined with chemometrics analysis. ${ }^{32}$ The qualitative characterization involved identifying fifteen compounds, among which was luteolin. The aim of this article was the fingerprint analysis of extracts from different species of the genus Scutellaria to estimate the identity of various plant materials by TLC and subsequent 
PCA. Thus, the experiments gave information about the composition of the plant extracts and were helpful in the construction of fingerprints of the examined herbs and varieties to facilitate their identification and assist in Scutellaria chemotaxonomy.

Selected standards of flavonoids and phenolic acids were separated using silica gel TLC plates with the mobile phase consisting of ethyl acetate-toluene-formic acid (5:4.9:0.1, v/v) for dichloromethane and methanolic extracts. Dichloromethane extracts were also developed using cyanopropyl-bonded silica gel with the following mobile phases: propan-2-ol- $n$-heptane-formic acid (5:4.9:0.1, v/v) and methanol-water-formic acid (6:3.9:0.1, v/v), and after drying, they were sprayed using the anisaldehyde reagent. In the case of methanolic extracts, the same nonaqueous eluent was used and the aqueous eluent consisting of methanol-water-formic acid (4:5.9:0.1, v/v). The presence of selected standards in Scutellaria species was confirmed.

\section{2 | Liquid chromatography}

Liquid chromatography (LC) is one of the most popular separation techniques in which the mobile phase is a liquid used to dissolve the samples to analyze. The separation takes place inside of a solid column. To do that, the sample, dissolved in the mobile phase, passes through the column, which is packed with a stationary phase composed of different kinds of particles. The differences in the interaction between the molecules of the sample and the particles in the column produce different transit times of the mentioned molecules through the column. In this way, the analytes of the sample leave the column separated into fractions at different times. Nowadays, LC is a very used technique mainly in small scales work to purify and isolate components from mixtures.

The solvents used in this technique are common and its sole objective is to dissolve all the species present in the sample and to have a polarity contrast, in order to make a gradual elution of all compounds. Acid solvents like phosphoric acid, formic acid, and acetic acid, organics solvents like methanol, acetonitrile, and acetone as well as water and some buffers are the most common solvents used as mobile phase, mainly in gradients programs of elution.

Although the solvents used are not many and are similar among the different works, in the case of the columns, there are even fewer differences. Practically all the studies agree to use a $\mathrm{C}_{18}$ column. $\mathrm{C}_{18}$ means that the molecules in the column particles have 18 carbon atoms but could be different molecules that fit with that having distinct atoms. Also, the columns could have different lengths.

The most commonly used detectors, coupled to LC, are those based on the technique of mass spectrometry, called mass/mass detectors (MS/MS), which are able to isolate and identify the components of the sample according to their mass/charge ratio by using electric and magnetic fields. Its ability to determine the molecular weight of the compound to be identified makes it one of the most powerful detectors.

Despite the fact that, for historical reasons, LC is the mother of all chromatography, and this distinction is usually made in some articles, the truth is that most articles that report studies with LC do so with HPLC columns. Knowing this and respecting this difference, made by the authors, we made this section and included it under the LC section.

By using LC-MS/MS, the group of Zhang could characterize 23 polyphenolic compounds from sesame oil, included luteolin with a LOD of $0.15 \mu \mathrm{g} / \mathrm{kg} .{ }^{33}$ Adding the technique of electrospray ionization (ESI), to produce ions from the analytes, coupled with the MS/MS detector, the group of Tomczyk could identify and quantified 31 compounds from Ziziphora taurica (subsp. Taurica), reaching a LOD value of $1.34 \mu \mathrm{g} / \mathrm{L}^{34}$

In the work of Han and co-worked, a rapid LC-QQQMS method (triple Quad MS) was used for simultaneous determination of luteolin and others eight major compounds in Eclipta prostrata L. in different habitats. ${ }^{35}$ The results yielded good analytical parameters and the speed with which these analyses can be performed stands out. Among the analytical parameters, is to highlight both the great stability of the method (residual standard deviation [RSD] intraday $1.56 \%$; RSD interday 1.60 ) as well as its very low LOD, $1.77 \mathrm{ng} / \mathrm{ml}$.

Although detection by MS/MS predominates in LC, there are other detection techniques such as diode array detector (DAD). Regarding that, in the work of MonagoMaraña et al., luteolin and other four more compounds from the extract of Paprika with and without "Protected Designation of Origin" were reported by using LC in series with DAD and fluorescence detection (LCDAD-FLD). In the case of luteolin, it was found in the concentration range of $16-19 \mathrm{mg} / \mathrm{kg}$ and $11-21 \mathrm{mg} / \mathrm{kg}$, respectively. ${ }^{36}$ Notice that in this work, remarkable recuperation values could be achieved (between $98.4 \%$ and $99.2 \%$ ) with excellent range values of intraday and interday stability, $0.79 \%-5.2 \%$ and $1.1 \%-7.7 \%$ RSD, respectively.

Table 1 summarizes the most relevant studies in relation to analytical determinations of luteolin (among others compound) by LC in the last years. 


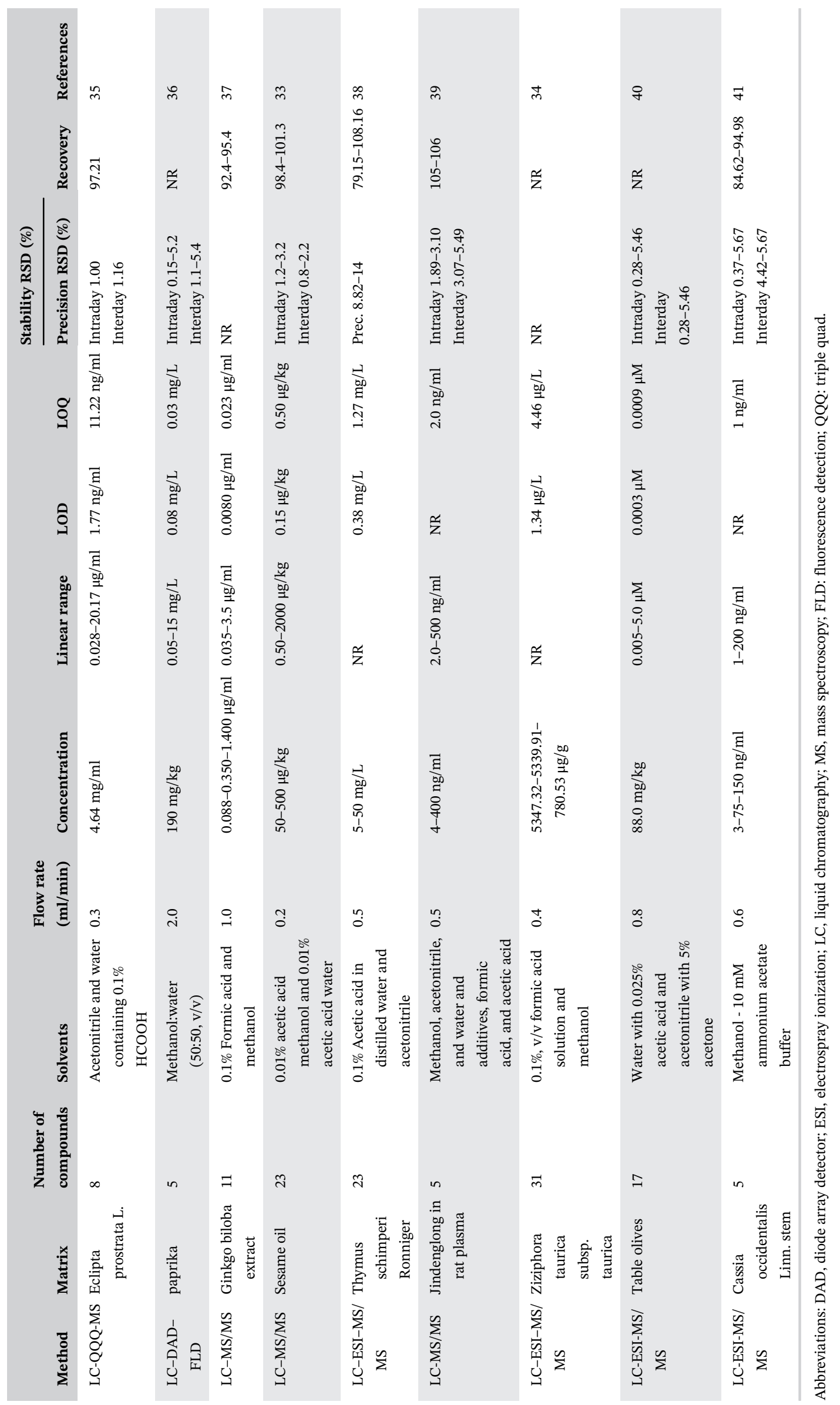




\section{3 | High-performance liquid chromatography}

HPLC is the technique commonly used for the separation of components in a mixture based on their differential distribution between mobile and stationary phases. It is a robust analytical technique mainly used for the qualitative analysis of non-volatile classes of compounds such as flavonoids. ${ }^{42}$ Since luteolin exists in complex natural matrices, the analytical methods implemented must be selective and sensitive.

In the sense, the application of HPLC can consist of both the qualitative and quantitative estimation of a particular composition of samples obtained from natural sources. The results of the qualitative analysis are evaluated based on the consistency in the retention time of reference standards and the compounds in the analyzed sample. Quantitative estimation is done based on the standard curve generated after reference standards are injected at different concentration levels. ${ }^{42}$

The column is a major component of HPLC. The column contains the particles used as stationary phase. Stationary phases usually have a particle size ranging between 3 and $50 \mu \mathrm{m}$ packing contained in a column with $2-5 \mathrm{~mm}$ bore size. Most of the separations are carried out on reversed-phase (RP) columns. ${ }^{43} \mathrm{RP}$ columns used in HPLC are more desirable and widely used for the analysis of multiple phytoconstituents routine HPLC methods use RP octadecyl silica columns for phenolic compounds. Silica-based $\mathrm{C}_{18}$ columns in RP-HPLC contain aliphatic $\mathrm{C}_{18}$ ligands, free silanols, water, and mobile phase modifier. ${ }^{43}$

Thus, in the vast majority of the works reviewed for the determination of luteolin, the RP was implemented, employing octadecyl $\mathrm{C}_{18}$-bonded silica columns, with the following conventional dimensions employed: column length $50-250 \mathrm{~mm}$, internal diameter $3.9-4.6 \mathrm{~mm}$, and particle diameter 1.8-10 $\mu \mathrm{m}$.

Mobile phase selection depends on the type and nature of compounds to be separated by HPLC. Generally, water and organic solvents such as methanol and acetonitrile along with small concentrations of acetic acid, formic acid and tri-fluoroacetic acid (TFA) are used for the separation of luteolin from different matrices by RP-HPLC.

Gradient elution is generally performed with a binary solvent system comprising an organic modifier and a slightly acidified aqueous phase. Instead of linear elution gradients, complicated gradient profiles, comprising several steps and applying various slopes, are often used. Thus, in the HPLC analysis of luteolin, separations were obtained by acidifying the mobile phase. A weakly acidic mobile phase suppresses ionization, thereby, increasing retention and decreasing the peak broadening that is caused by the formation of the deprotonated form. ${ }^{43}$

For HPLC analysis, the selection of an appropriate column temperature and injection volume is another factor influencing detection. In this sense, the analyzes for luteolin were carried out between 25 and $30^{\circ} \mathrm{C}$ and injection volumes between 1 and $20 \mu \mathrm{l}$.

Another aspect to consider in the detection is the selection of a suitable detector. Detectors play a significant role in the precision, accuracy, and stability during the detection of a specific compound from complex samples. ${ }^{44}$ The detectors used most often are based on UV absorbance or, less frequently, visible light absorbance. In analysis of luteolin, UV detectors can be used, due to the presence of aromatic rings in the molecule. Flavonoids display two UV-vis absorption maxima: an absorption band in the region of $240-285 \mathrm{~nm}$ ascribed to the A-ring, and a second band at $300-550 \mathrm{~nm}$ due to the B-ring. In particular, luteolin shows a maximum in the absorption band between 300 and $380 \mathrm{~nm}^{43}$

The use of a UV detector that performs the analysis only at one wavelength is limited in studies with mixing of components in the matrix, because the absorption maxima of different compounds maybe similar. ${ }^{43}$ The solution to this problem is the use of a UV-diode array (UV-DAD), allowing for continuous adjustment of the wavelength across the UV-visible interval of the spectrum. Although, for luteolin, the detection limits (LODs) in HPLC-DAD were like those for UV detection.

Compared to the above detectors used in luteolin analysis, HPLC-MS offers higher sensitivity, selectivity and versatility. This type of detection is especially useful for reliable identification in complex matrices. The use of HPLC-MS obtains simultaneously information regarding not only the type, the amount, and the retention times of the particular compounds but also their molecular weight and fragmentation pathways. ${ }^{45}$

The analysis with MS detector may be performed with different types of ionization in the ion source. In the case of luteolin, ESI was most commonly used.

Although luteolin may be determined in both positive $[\mathrm{M}+\mathrm{H}]^{+}$and negative $[\mathrm{M}-\mathrm{H}]^{-}$ion modes, the negative ionization mode was used in most cases. An important element of the MS detector is the analyzer. In the analysis of luteolin, the most commonly used analyzers were quadrupole and triple quadrupole. Due to the low resolving power of a single device, tandem mass spectrometers are much more frequently used. Such systems not only are more selective and sensitive but also allow for quantitative analysis, provide information about the structure of the compound, and characterize the fragmentation pathways of a single compound present in a complex matrix. Currently, in the analysis of flavonoids, a 
combination of several detectors, mainly UV-MS, is most used. $^{42}$

HPLC still is the ideal analytical separation technique used commonly for quantitative and qualitative analysis of natural compounds. ${ }^{46}$ Various studies have reported the optimized chromatographic conditions used for the separation of flavonoids from complex samples. ${ }^{42}$

Ma et al. proposed a method based on HPLC coupled to a UV detector (set at $350 \mathrm{~nm}$ ) for the simultaneous determination of seven compounds in bamboo leaves, included luteolin. ${ }^{47}$

Calibration curves showed a linear regression between 1.54 and $24.72 \mu \mathrm{g} / \mathrm{ml}$ for luteolin. LOD and LOQ were $0.19 \mu \mathrm{g} / \mathrm{ml}$ and $0.58 \mu \mathrm{g} / \mathrm{ml}$ for luteolin, respectively, the intraday precision (RSD, \%) determined for three concentration levels was less than $1.07 \%$, and the stability evaluated during $24 \mathrm{~h}$ (RSD, \%) was $2.58 \%$. The recoveries for luteolin were in the range of $107.39 \%-109.26 \%$ with an RSD of $0.83 \%$.

Yin et al. proposed another very interesting HPLC method coupled to UV (set at $350 \mathrm{~nm}$ ). ${ }^{48}$ First, several experimental parameters that affected the extraction performance, such as the solvent, the microwave irradiation time, temperature, and solid-to-liquid ratio, the type of adsorbent, the amount of sample, the adsorption time, and volume of the eluent were optimized by Box-Behnken experiments design. Then, they developed a method for the simultaneous determination of seven flavonoids, including luteolin, in Veronicastrum latifolium (Hemsl.). Calibration curves were linear in the range of 3.906-250 $\mu \mathrm{g} / \mathrm{ml}$ for luteolin. The intraday and interday precision RSD were $1.41 \%$ and $3.93 \%$, respectively. This method had a LOD of $0.027 \mu \mathrm{g} / \mathrm{ml}$ and recoveries of $98.87 \%$.

Zhang et al. described an interesting methodology based on gradient HPLC coupled to photo diode array detector (PDA) for determination of content of 16 phenolic compounds of seeds from nine tree peony (Paeonia section Moutan DC.) species native to China. ${ }^{49}$ UV detection was recorded between 200 and $400 \mathrm{~nm}$. Calibration curves were linear in the range of $1.15-57.3 \mathrm{mg} / \mathrm{ml}$ for luteolin. These authors reported a LOD and LOQ to luteolin of 0.11 and $0.35 \mathrm{mg} / \mathrm{L}$, respectively. The method yielded very satisfactory results when it was applied to tree peony, with the intraday and interday precision RSD for luteolin were of $2.52 \%$ and $2.98 \%$, respectively, and recoveries of $96.19 \%$.

$\mathrm{Du}$ et al. proposed a method based on HPLC with diode array detector (DAD) to the simultaneous determination of 11 components in Yinzhihuang preparations and their constituent herbs. ${ }^{50}$ Calibration curves were linear in the range of $0.01-1.0 \mu \mathrm{g}$ for luteolin. The DAD spectra were recorded between 190 and $400 \mathrm{~nm}$. The LOD and LOQ for luteolin were 0.0015 and $0.0051 \mu \mathrm{g}$, respectively. Recoveries of luteolin were between $98.1 \%$ and $110.1 \%$. The intraday and interday precision RSD for luteolin were less to $1.04 \%$ and $1.2 \%$, respectively.

Sarikahya et al. described several flavonoids and phenolic compounds in 19 different Cephalaria species by HPLC-MS/MS. ${ }^{51}$ This method was developed for quantitation of thirty-four components, including luteolin, using reverse phase in ESI mode. Calibration curves were linear in two range $0.3-25.2 \mathrm{ppb}$ and $3.0-102.3 \mathrm{ppb}$, for luteolin. The recovery of the developed method was $99.8 \%$ to luteolin. LOD and LOQ values were of 0.7 and $3.5 \mathrm{ppb}$, respectively.

By using HPLC-MS/MS, Yan et al. could characterize 20 compounds, such as flavonoids, phenolic acids, and alkaloids, included luteolin, in abri herba and abri mollis herba. ${ }^{52}$ Calibration curves were linear in the range of $0.13-4680.00 \mathrm{ng} / \mathrm{ml}$ for luteolin, with LOD and LOQ of 0.01 and $0.03 \mathrm{ng} / \mathrm{ml}$ for luteolin, respectively.

In addition, the technique of ESI to produce ions from the analytes, coupled with the MS/MS detector, allowed Zhang to identify and quantify thirteen compounds from Commelina communis. ${ }^{53}$ Calibration curves were linear in the range of $0.0083-0.53 \mu \mathrm{g} / \mathrm{ml}$ for luteolin, reaching a LOD and LOQ of 0.0066 and $0.0264 \mu \mathrm{g} / \mathrm{ml}$ for luteolin, respectively.

On the other hand, to a lesser extent, developments with HPLC-quadrupole-time of-flight (Q-TOF)-MS were implemented. Thus, Yang et al. determined 15 Flavonoids in Scutellaria barbata-Hedyotis diffusa Herb Pair by HPLC Q-TOF/MS. ${ }^{54}$ These authors reported a LOD and LOQ to luteolin of 0.75 and $2.38 \mathrm{ng} / \mathrm{ml}$, respectively. The method yielded very satisfactory results, with the intraday and interday precision RSD for luteolin were of $2.62 \%$ and $1.58 \%$, respectively, and recoveries of $100.5 \%$.

Shui et al. determined the content of luteolin in five crops of Chrysanthemum morifolium Ramat (Chr) by HPLCUV method. ${ }^{55}$ His proposal was to investigate luteolin content in different Chr cultivates by implementing multispectral images (MSI). A combination of MSI with a PCA and least squares-support vector machines (LS-SVM) was applied to classify Chr cultivars. PCA derived from the spectral and morphological features data of the samples explained $99.61 \%$ for summing up the first three principal components and the LS-SVM model achieved 98\% discrimination accuracy in the prediction set. Additionally, partial least squares (PLS) and LS-SVM models were obtained to predict performance for luteolin content determination, with prediction correlation coefficient (Rp) of 0.949 and 0.965 , and root mean square error of prediction (RMSEP) of 0.387 and $0.314 \mathrm{mg} / \mathrm{g}$, respectively.

Table 2 lists the diverse applications in natural product analysis studied using HPLC method for qualitative and quantitative analysis of luteolin, in the last years. 

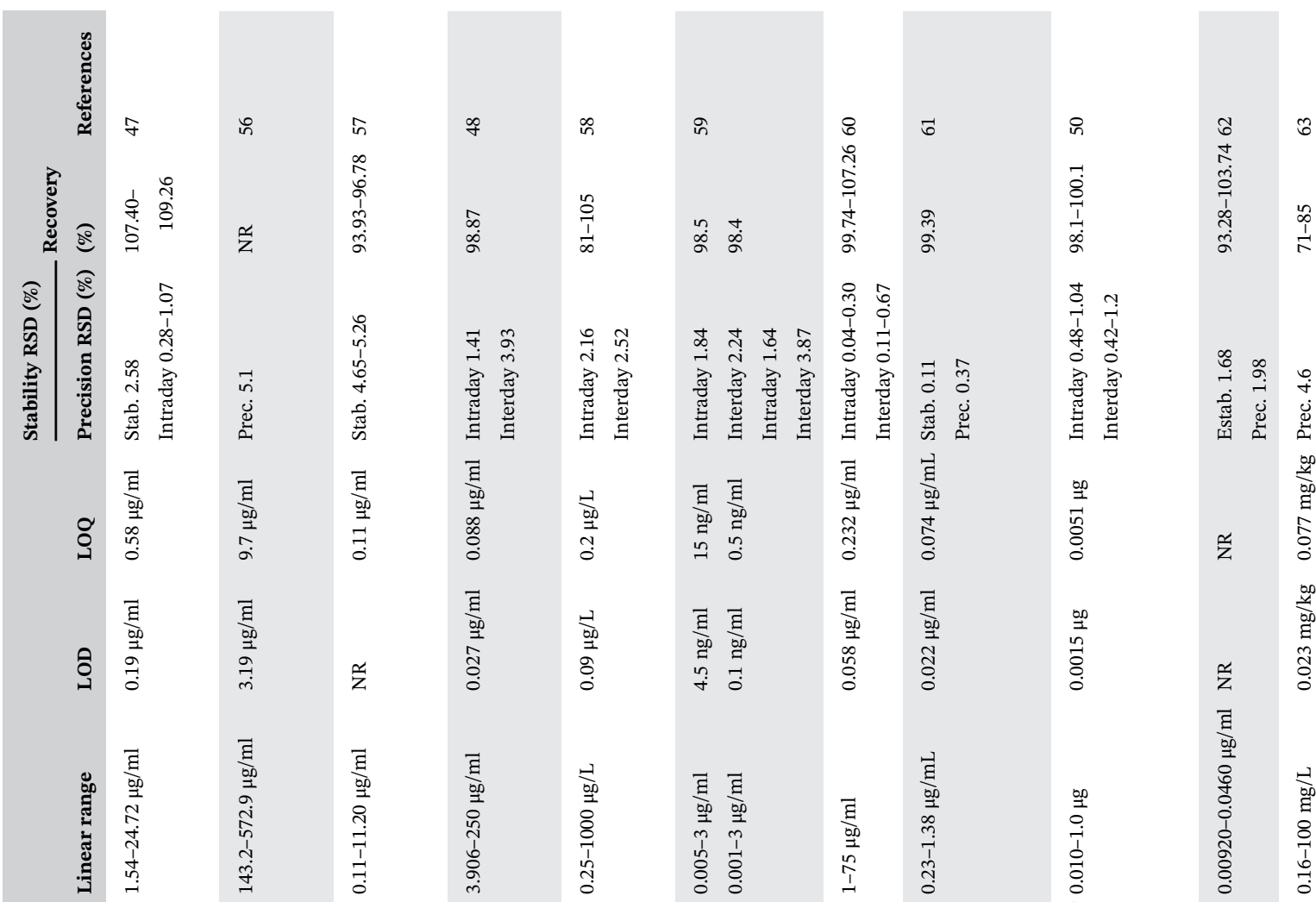

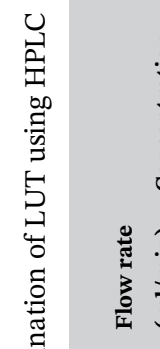

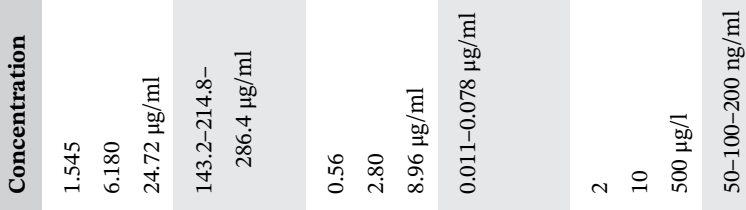

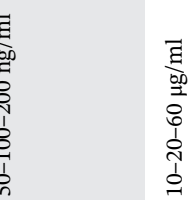

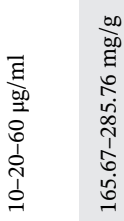

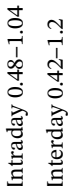

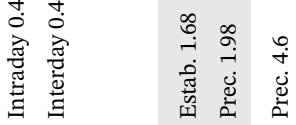

紫

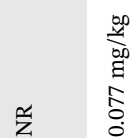

है

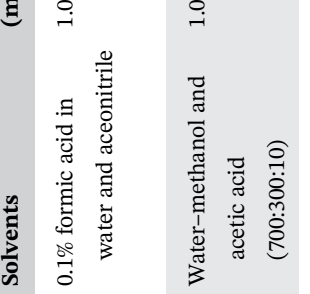

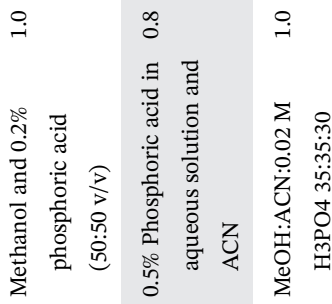

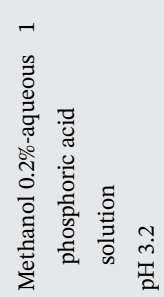

$\stackrel{\infty}{\circ}$

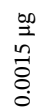

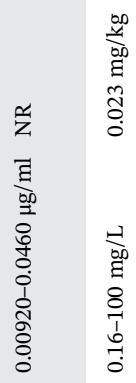

0
$\frac{0}{0}$
0
0
0
0
0
$\frac{0}{0}$
$\frac{\pi}{0}$

늘

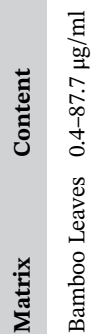

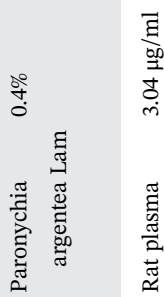

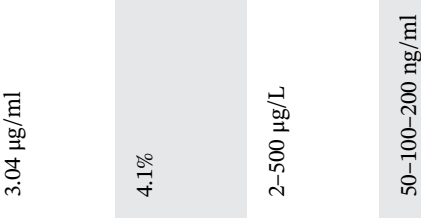

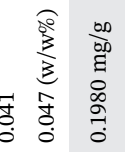

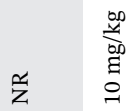

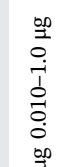

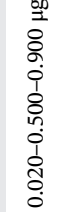

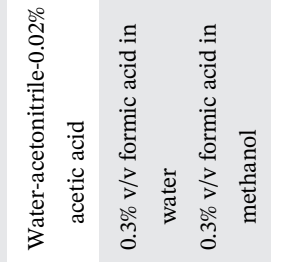

$\stackrel{\circ}{-}$

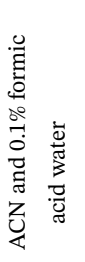

$\stackrel{9}{\circ} \stackrel{\circ}{\circ}$

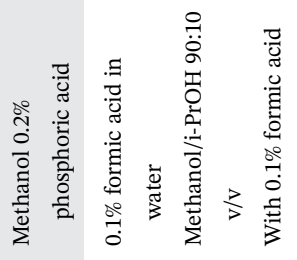

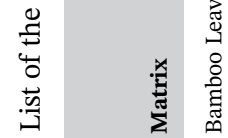

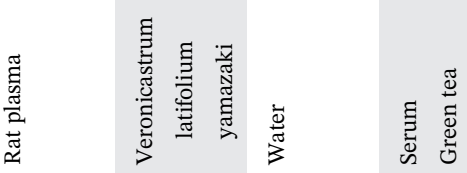

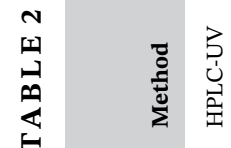

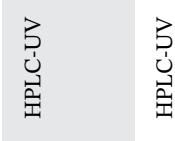

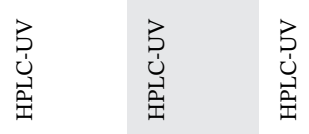

䓵

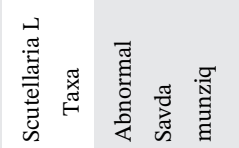

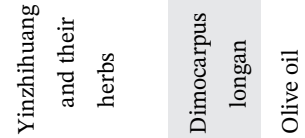

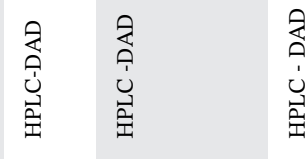

㤂 


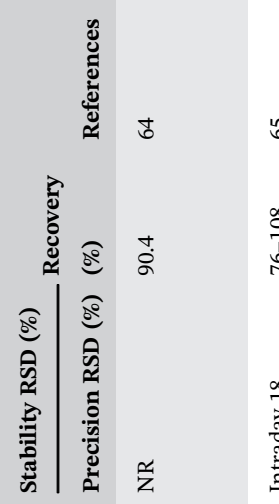

II

in

in:

;

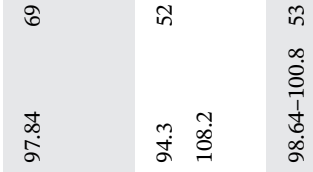

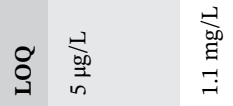

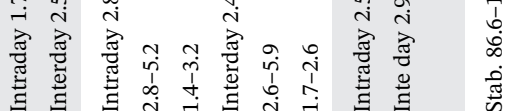

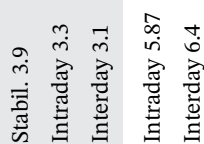

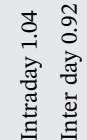

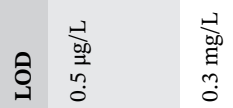

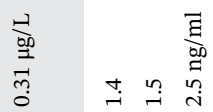

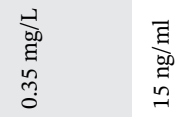

를

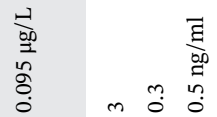

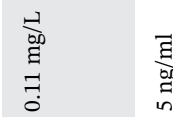

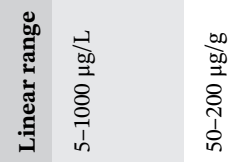

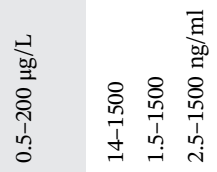

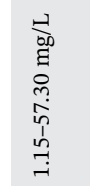

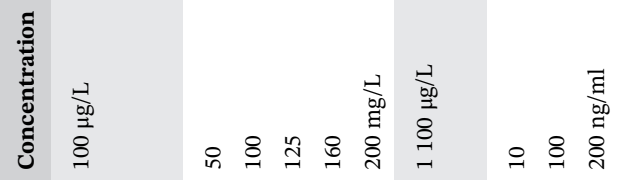

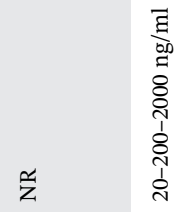

䍃骨
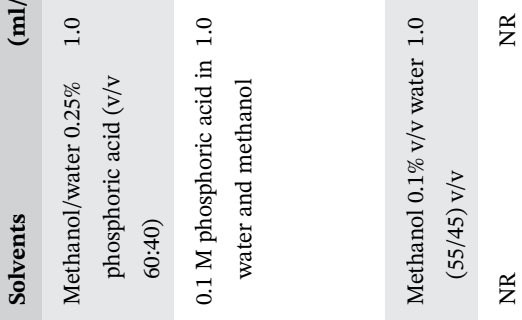

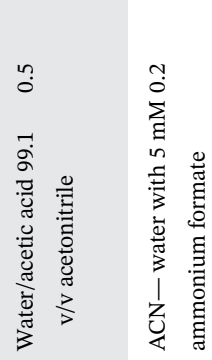

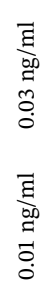

छ

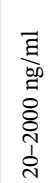

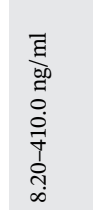

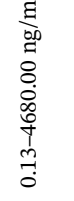

寻
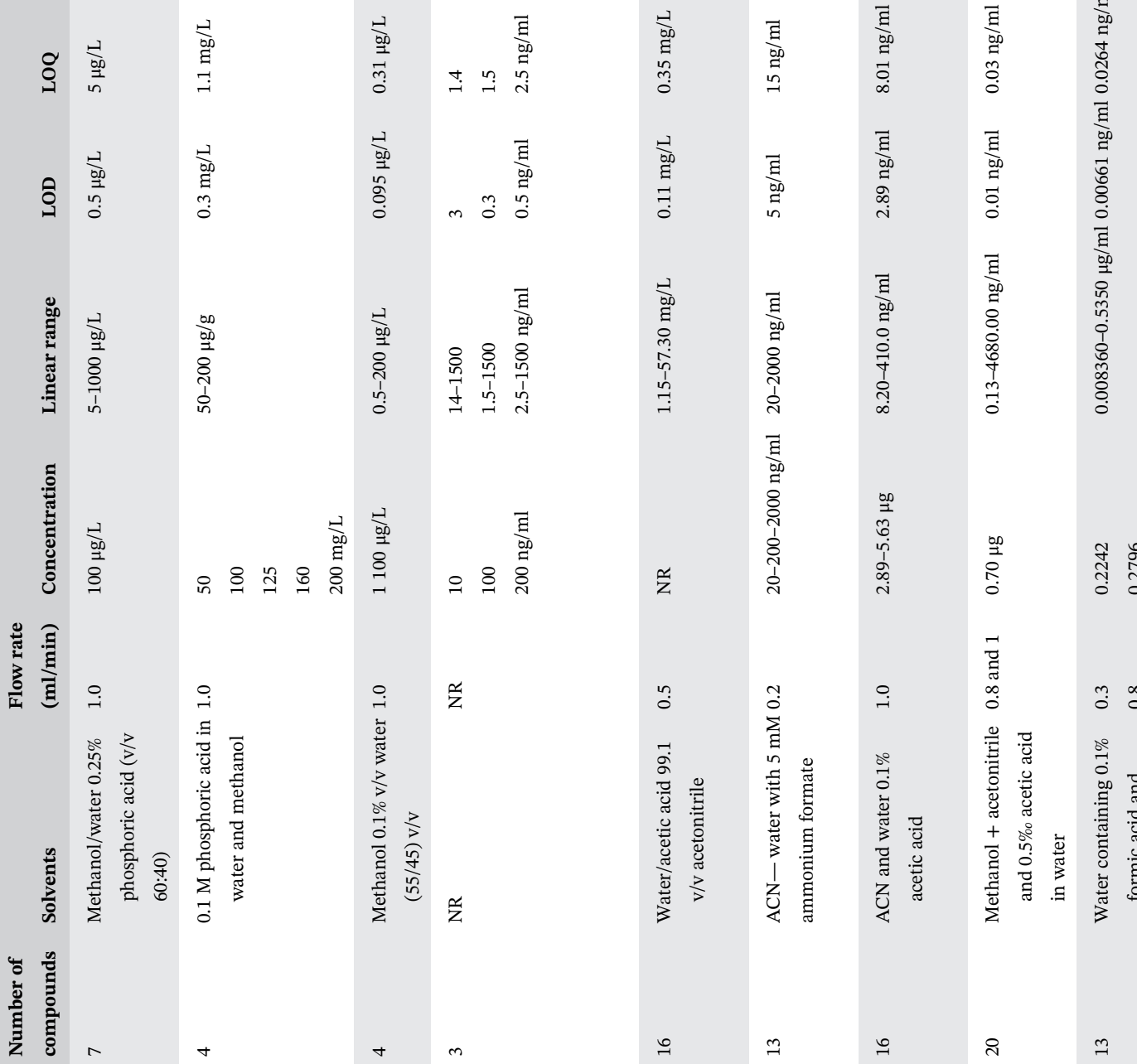

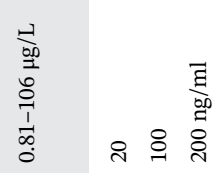

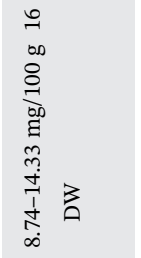

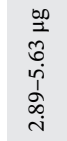

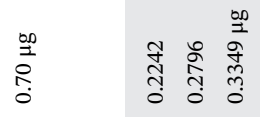

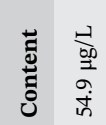

త్త్ర

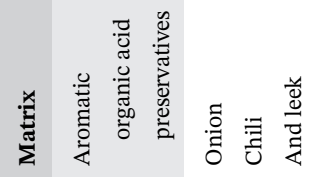

总总总言

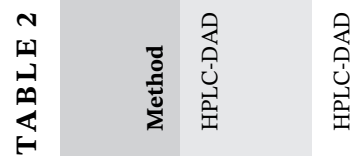

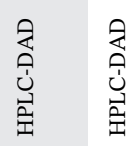

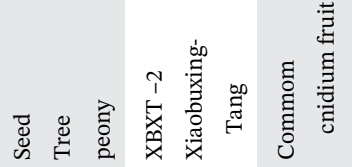

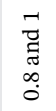

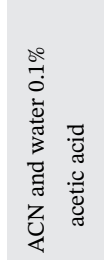

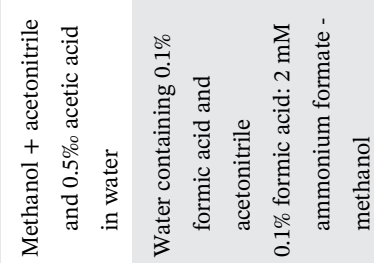


TESIO AND ROBLEDO

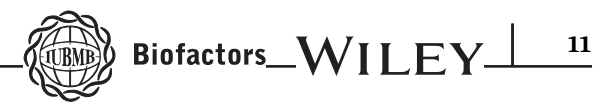

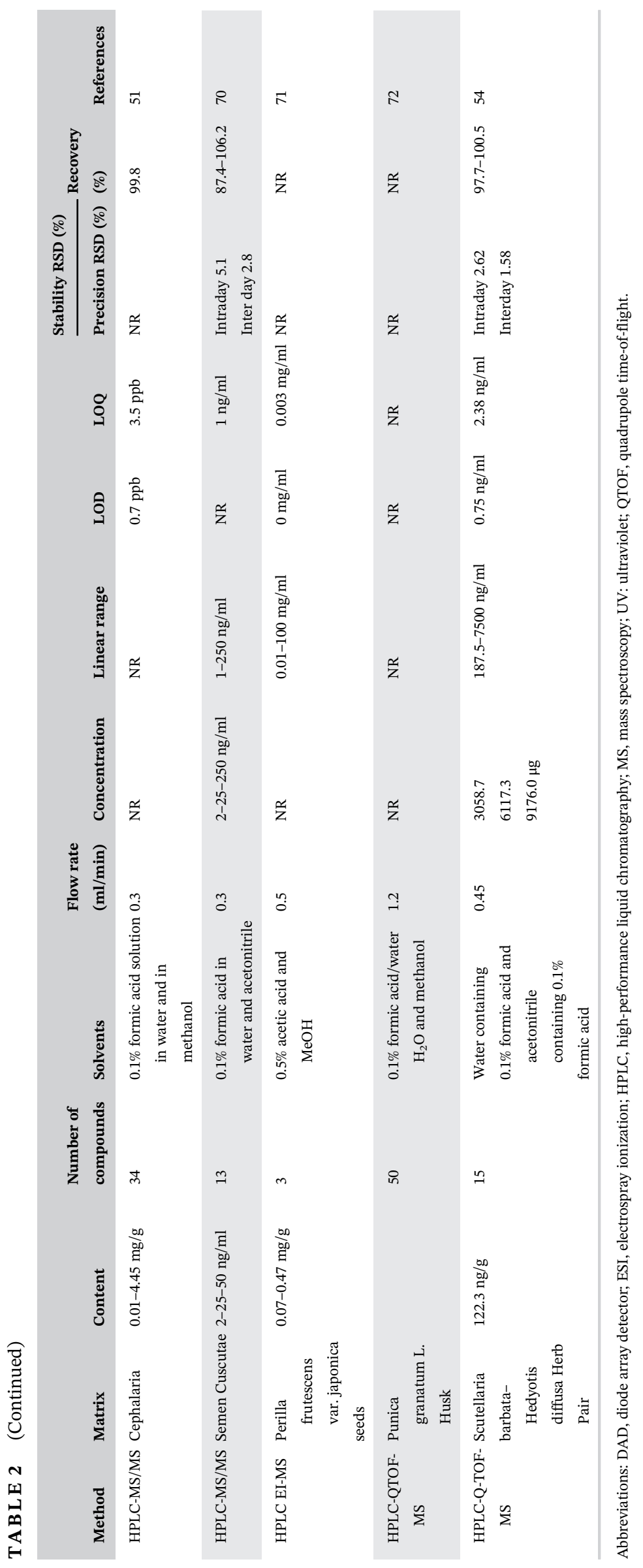




\section{4 | Ultra-high performance liquid chromatography}

Ultra-high performance liquid chromatography (UHPLC, usually called ultra-high pressure liquid chromatography) is a subcategory of HPLC technique able to operate up to 600 bar (8700 psi), which use particles of sub- $2 \mu \mathrm{m}$ size and a very low dispersion. These characteristics allow to both save solvent and increase performance reducing run times. ${ }^{73}$

UHPLC is one of the last developed chromatographic techniques, although the first continuous reports in time are from the early 2000s, there is a marked rise in the number of publications around 2010. Among several analytes studied by UHPLC, luteolin appears like others, in the last few years. For that reason, there are only a few works using UHPLC to carry out analytical determinations of luteolin. A list of the most relevant work, to our criteria, is shown in Table 3.

Among them, the work of $\mathrm{Hu}$ stands out because of its analytical parameters. Working with grape juice, they reach a value of $0.5 \mathrm{ng} / \mathrm{ml}$ in the determination of luteolin (analyzing three compounds at the same time). ${ }^{77}$ Although having excellent values of stability and recovery, it lacks a wide lineal range, which is extremely important at the time to work with samples of unknown analyte concentration.

Note that is easy to see in Table 3 how the simultaneous compound analysis is improved by the use of MS/MS reaching to analyze 26 different compounds drawn on the benefit of a triple quadrupole.

\section{5 | Ultra performance liquid chromatography}

UPLC, is defined by its creator, the company Waters ${ }^{\circledR}$, as the chromatographic technique that uses sub- $2 \mu \mathrm{m}$ particle in low dispersion columns and in combination with high pressure (1034 bar; 15,000 psi).

In a very brief comparison between UPLC and HPLC, we can say that UPLC decreases process cycle time, reducing cost and the use of solvents and even the sample injection volume, increasing the sample throughput. Compared to HPLC, UPLC column (with an inner diameter of $0.75-1.8 \mathrm{~mm}$ vs. HPLC 3-10 nm) suffer higher backpressure which reduces its useful life. In the same line, the very small particles used in the UPLC columns, in most of the cases are not renewable.

Related to UHPLC, the higher loading capacity is close to three times higher using fully porous particle columns in UPLC than using superficially porous particle columns on a UHPLC system. (UPLC versus UHPLC:
Comparison of Loading and Peak Capacity for Small Molecule Drugs - Kenneth J. Fountain)

Like the case of UHPLC, UPLC is one of the last developed techniques, by Waters in 2004. Although today, there are thousands of reported where this technique is used, it is still not as popular as the HPLC technique and that is why the number of works found, in particular for luteolin determinations, is less. Table 4 describes the most relevant studies, in our judgment, with relation to analytical determinations that include luteolin, among other analytes of interest, in a wide variety of matrix, mainly extracts, but not limited to them.

As can be seen from the bibliography cited in Table 4, the determinations performed using UPLC in most of the cases are focused in improving the analytical parameters at the expense of working with a lower number of analytes. This does not necessarily have to be the case, but it is what we find in most cases. Likewise, it can be observed how the used flows are lower, but by using smaller volumes of samples and being more efficient in the technique, this does not increase the analysis time, but the opposite.

Within this field of work, the one carried out by $\mathrm{Li}$ and co-workers, ${ }^{86}$ in which determines simultaneously 18 chemical constituents in an antitussive used in the traditional Chinese medicine. This work stands out not only for the number of simultaneous determinations, of course, LUT including, but it also reaches excellent values in terms of LOD $(1.562 \mathrm{ng} / \mathrm{ml})$ and linear range $(25-1600 \mathrm{ng} / \mathrm{ml})$. Possibly this linear range of three orders of magnitude, which in terms of linearity is very good, become an issue to work with such low concentrations, especially if the concentration of the sample to be determined is completely unknown.

\section{3 | ELECTROCHEMICAL DETERMINATIONS}

A quick search with the keywords \{"luteolin" + "electrochemical" + "determination"\} show us a constant article production with a marked growing of citations (Figure 3 $(\mathrm{A}, \mathrm{B})$ ).

Several articles report an analytical technique coupled with an electrochemical device used as a sensor to quantify the desired analyte in the sample. In this section, we will not be occupied to them, instead, will be focused on pure electroanalytical determinations, devices usually called "electrochemical sensors."

Although most articles in this field choose differential pulse voltammetry (VPD) as electrochemical technique for its intrinsic characteristics beneficial for quantification (i.e., time consumption, sensibility, portability), there 


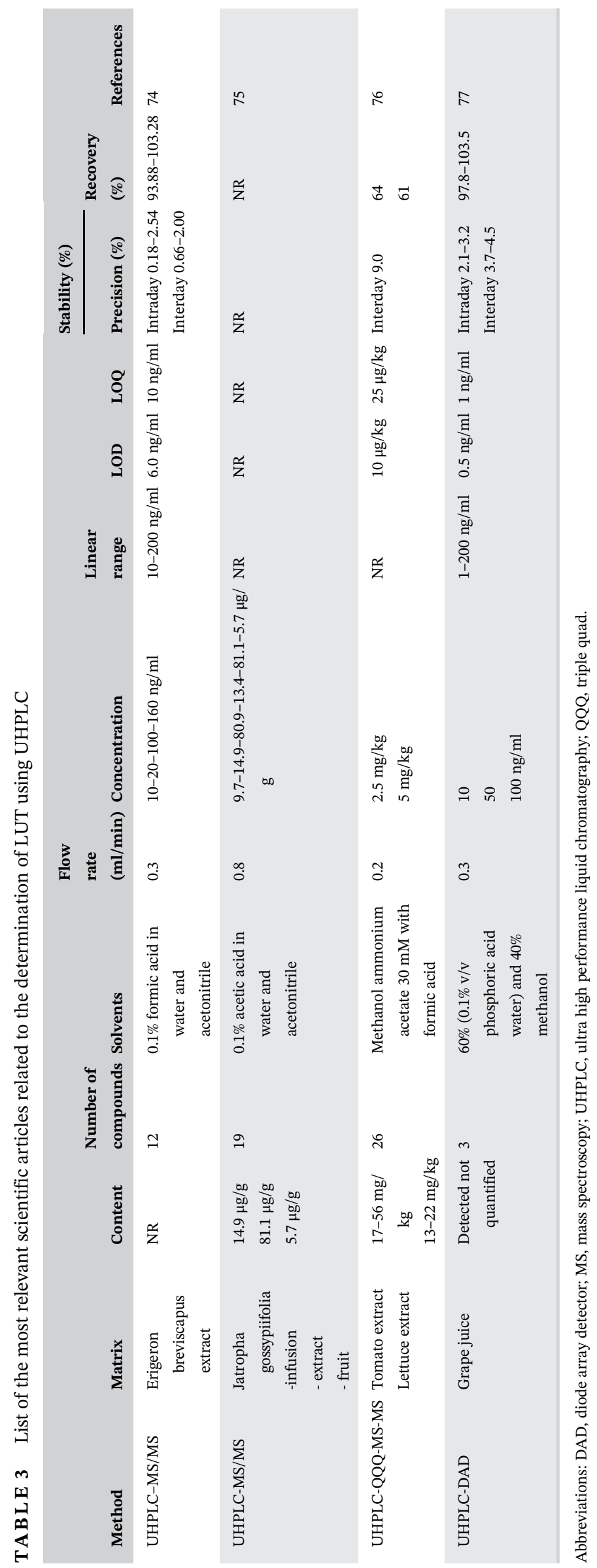




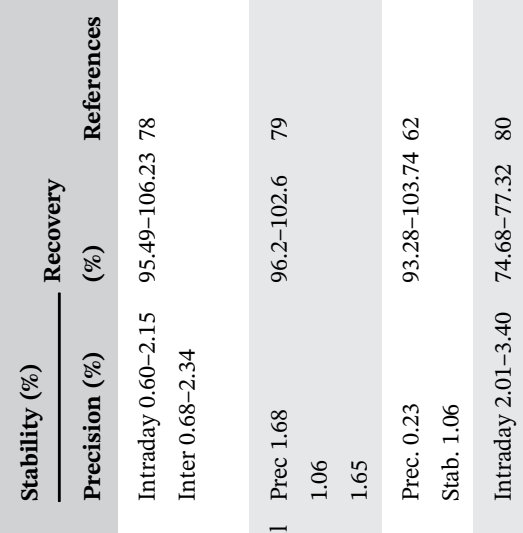

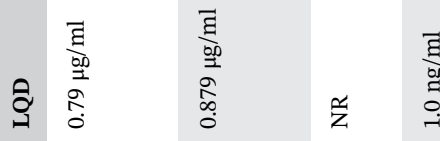

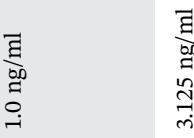

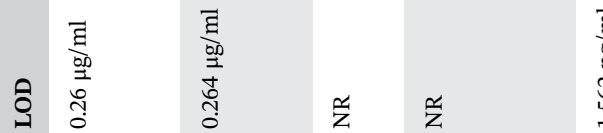

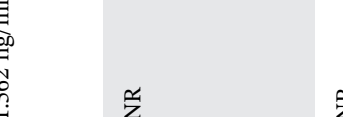

ì

ำ.

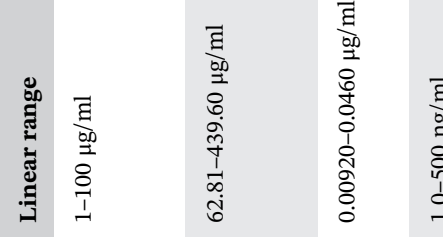

号

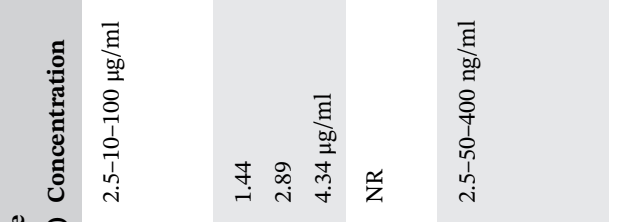

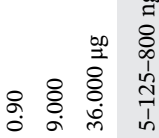

妾

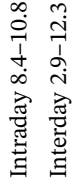

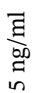

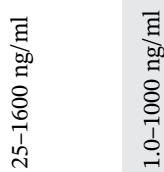

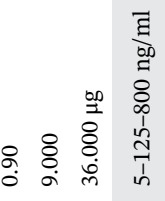

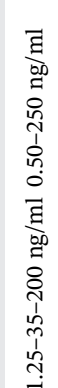

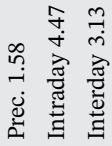

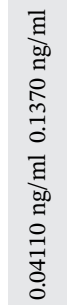

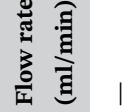

高毒君者

言 青

ž

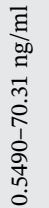

造

$\underset{\Xi}{\Xi}$

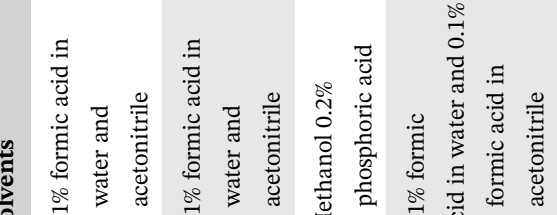

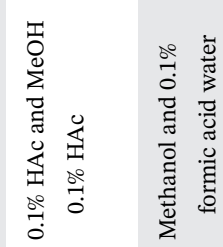

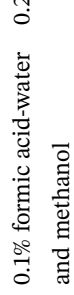

范
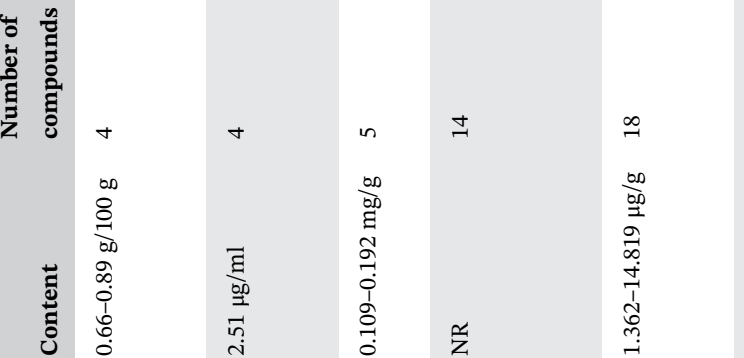

苞

苑

$\stackrel{2}{ \pm}$

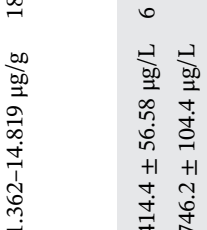

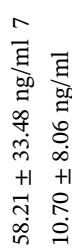

¿

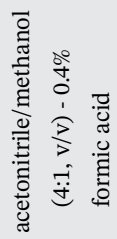

$\stackrel{4}{.0}$ 
are some that make use of other ones like linear sweep voltammetry (LSV), square wave voltammetry (SWV), and square wave anodic adsorptive stripping voltammetry (SWAASV), which achieve very good results.

In the next lines, we have summarized the articles according to our opinion, which produced the most relevant information in the field of electroanalytical sensor for luteolin determination in the last years.

There is a huge spectrum of samples in which luteolin has been quantified by electrochemical methods, among them: foods (tomato, carrot, peanut hulls, paprika, etc.), drinks (watermelon juice, Grape juice, Chrysanthemum tea, etc.), medicines (Lamiophlomis rotata Kudo and Duyiwei capsules, etc.) and human body related (urine, serum, thyme).

Most of the sample preparations are very simple, but could include dried, filtration and/or extractions steps. Is worth to mention that the usual chemical compound to extract luteolin is ethanol, which together with the characteristics of the electrochemical methods, turns it into a green and sustainable analytical method.

To sum up, an ideal electrochemical sensor has the features of high selectivity (determination of an analyte in presence of interfering substances), high stability (it can be used for a long period of time), high sensitivity (it allows the obtention of low LOD) and, finally, a wide linear range.

Regarding to the LOD, the work reported by Fu and Liu et al. reaching $1.7 \mathrm{pM},{ }^{87}$ together with the articles published by Dong and Guo et al., what reaches concentration of $3.3 \mathrm{pM},{ }^{88}$ and the work of $\mathrm{Qu}$ and $\mathrm{Lu}$ et al. obtaining a LOD value of $3 \mathrm{pM},{ }^{89}$ are the most promising in the field. It is noteworthy, in the case of these last two studies, in addition to extremely low detection limits, they achieve the measurement in a very short time, $60 \mathrm{~s}$ and $30 \mathrm{~s}$, respectively. An additional improvement of the methods developed by $\mathrm{Qu}$ and $\mathrm{Lu}$ et al. is the electrode stability. The electrode, a three-dimensional nickel oxide and Ni-metal-organic frameworks nanoarrays modified titanium mesh (NiO@Ni-MOF/TM) could be suitable for its use for 4 weeks with $97.6 \%$ of its original response.

Continuing with this topic, it is good to note that most of the reports about the stability of the electrode are in the range between hours to a few weeks, usually no more than two. Is in this context it is where the gold-palladiumreduced graphene oxide nanofilm modified glassy carbon electrode (Au-Pd-rGO/GCE) reported by Tong and co-workers stand out, achieving a 3 months stability. ${ }^{90}$

The time that the analysis takes is not a minor issue. There are works that need to extend the experimental time until $25 \mathrm{~min}$ to reach the extremely LOD reported. In general, we could say that the electrochemical measurement takes around $3 \mathrm{~min}$ and clearly there is a compromise between LOD and measurement time. 

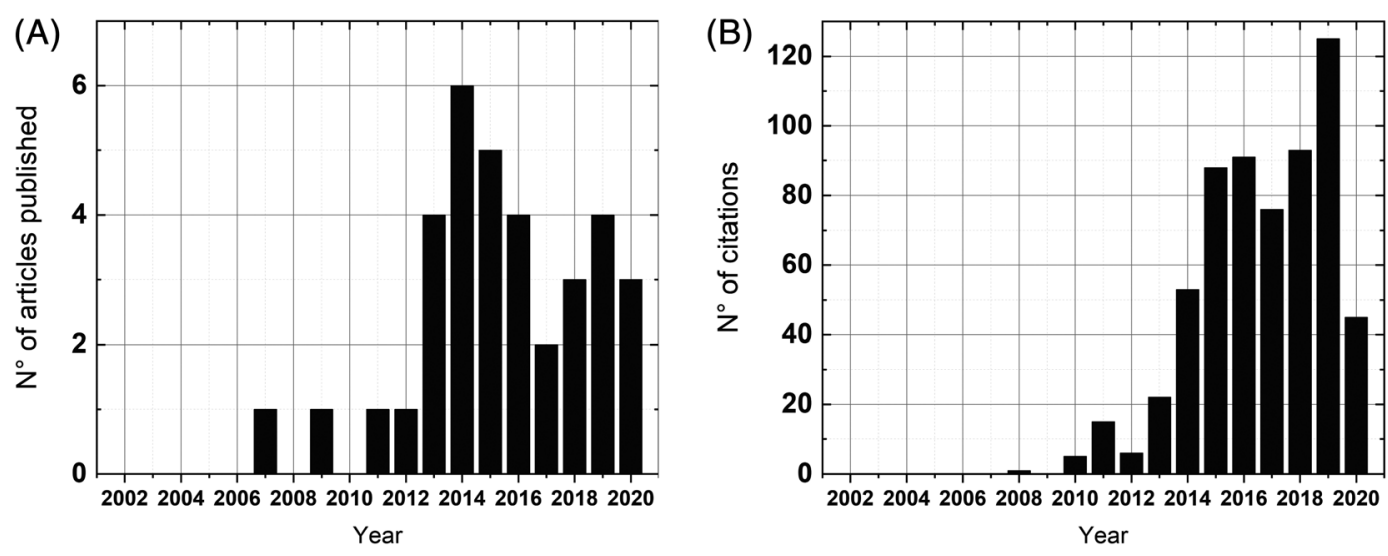

F I G U RE 3 (A) Time evolution of articles published and (B) citations of the same. Keywords used: \{"luteolin" + "electrochemical" + "determination"\} (source: Web of Science)

Finally, an item that involves cost, portability, and stability is the simplicity of the electrode and/or the method used. At this point, it is important to highlight the work carried out by the group of Galeano-Díaz in which by moving the focus to data analysis instead of the electrode modification, they get good results (even in selectivity) through the use of a bare GCE together with a data analysis based on partial least squares analysis (PLS). ${ }^{91}$

Probably in the case of luteolin determination in real samples, it is more important that the sensor has a wider linear range than that it has an extremely low LOD. In a sample with an unknown value of luteolin concentration, it is important that the measured value falls within the calibration curve to avoid errors. Although it is interesting to have the ability to quantify analytes in the order of picomolar concentrations, in the case of luteolin it is not essential, since the concentrations usually to be determined are much higher. It is at this point where we want to highlight the work of Zheng's group and, one more time, the work of Tong's group in which values of a lineal range of $\left(1 \times 10^{-8}\right.$ to $\left.1 \times 10^{-5}\right) \mathrm{M}$ and $\left(1 \times 10^{-8}\right.$ to $\left.8 \times 10^{-5}\right) \mathrm{M}$ are, respectively, reported.

In addition to the previously mentioned parameters, there are others that are important and characterize an electrochemical sensor, such as the potential and $\mathrm{pH}$ at which they work, the percentage of recovery when the developed method is tested against a standardized method and its sensitivity, among others.

Finally, as mentioned in the introduction, chemometrics is an area that has become very important. In turn, within chemometrics multivariate calibration is one of the most prominent. In multivariate calibration, methods based on the data processing of the vectorial type are used, that is, spectra or other data like voltammograms, called first order, for the simultaneous determination of two or more analytes or an analyte in the presence of interferents.
In this sense, Tesio et al. ${ }^{92}$ developed a calibration model to simultaneous electroanalytical determination of luteolin in the presence of rutin in a pharmaceutical formulation using artificial neural networks. The methodology is based on square wave voltammetry at glassy carbon electrodes modified with multiwalled carbon nanotubes dispersed in polyethylenimine. According to values declared by the manufacturer, differences of $7.4 \%$ and $8.0 \%$ were calculated for luteolin and rutin, respectively. Results obtained with electroanalytical methodologies were in very good agreement with those obtained by HPLC.

Table 5 gathers the most important data extract from the articles reporting electrochemical determinations of luteolin published in the last years.

\section{4 | OTHERS ANALYTICAL TECHNIQUES RELATED TO THE LUTEOLIN QUANTIFICATION}

It is clear that the field of - luteolin quantification-is dominated by chromatographic techniques, followed, in a second place in popularity, by the electrochemical methods. Nevertheless, there are some other relevant techniques that do not fit into either of these two categories and we think they deserve being mentioned. The fact that these techniques are less widespread does not imply that their results are not competent enough compared to the popular ones. In this section, we will make a small brief of the articles we find most interesting.

Fluorescence spectrometry is a very powerful analytical technique. The work of Huang and co-workers shows its application to the quantification of luteolin. ${ }^{112}$ In the proposed method, they use luteolin to quench the fluorescence of ofloxacin, which works in the lineal range from $2.00 \times 10^{-7}$ to $8.00 \times 10^{-5} \mathrm{M}$. They can achieve a 


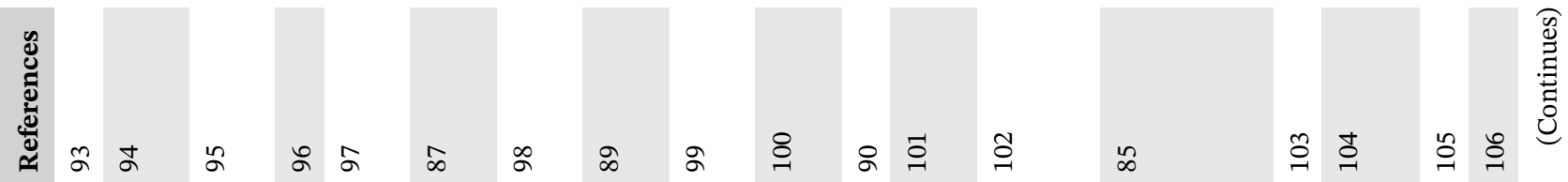

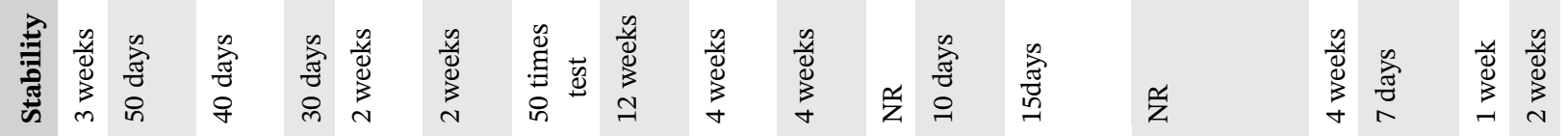

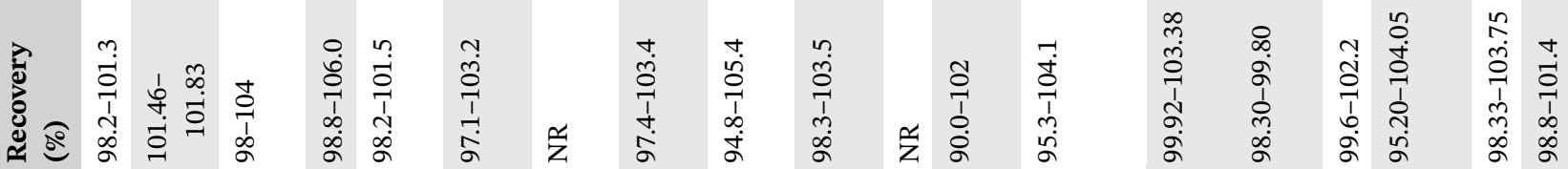

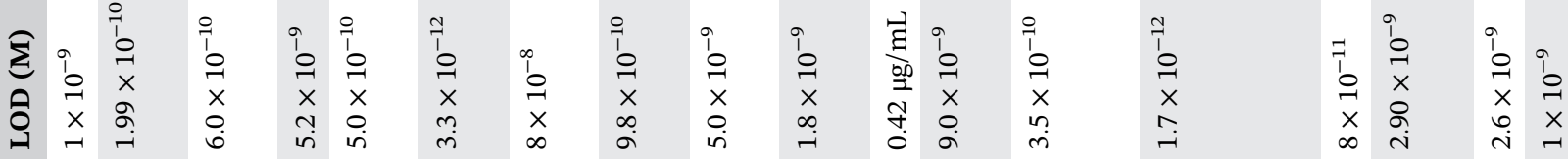
$\sum \begin{array}{lll}n & i & i \\ 0 & 0 & 0\end{array}$ $x$ $\bar{x} \times$

Е in

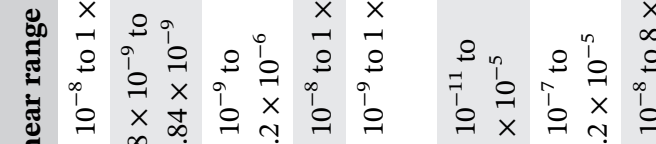

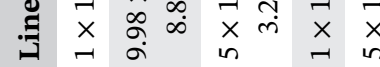

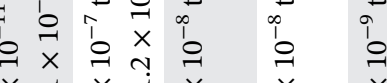

घี $\stackrel{i}{x}$

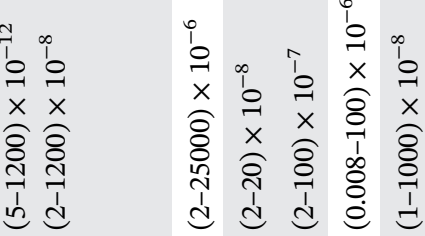
䠌

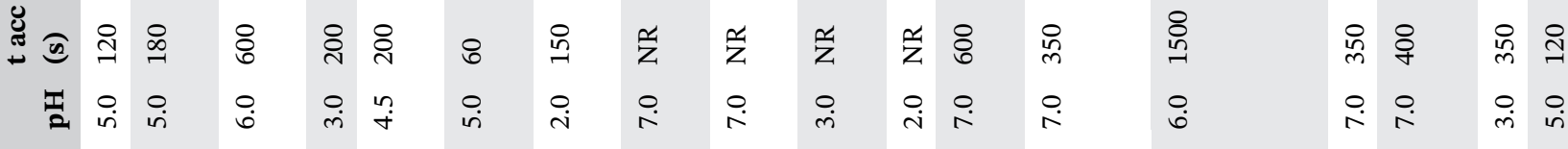

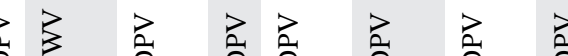

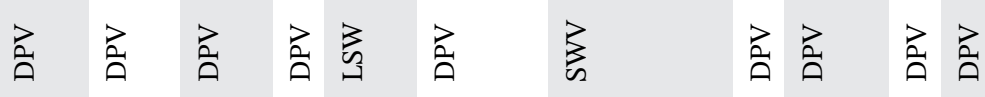

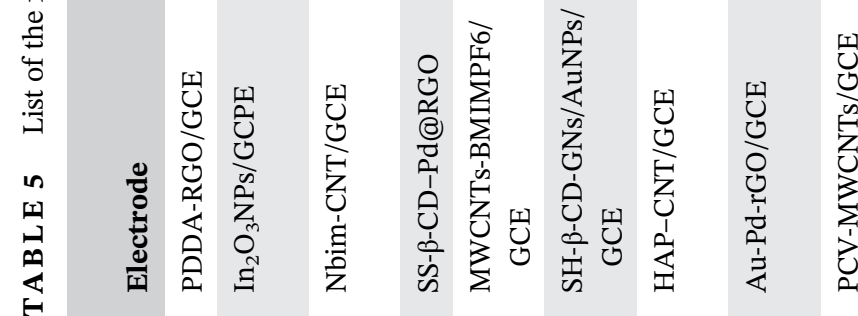

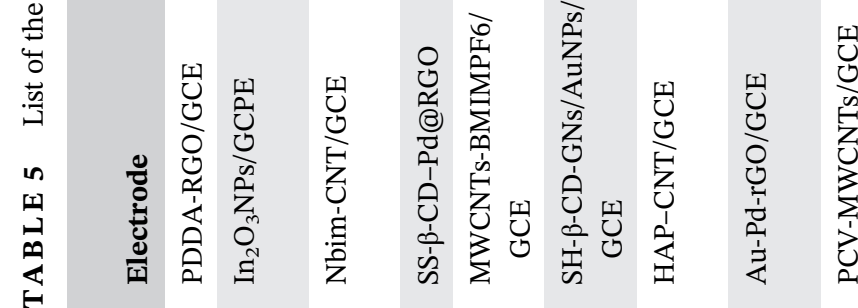

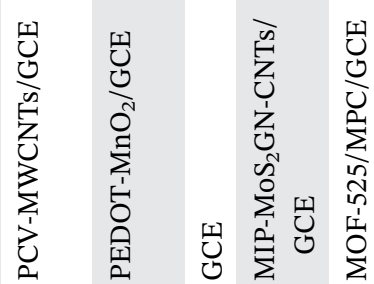

崩

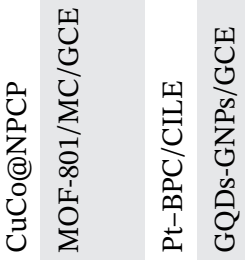




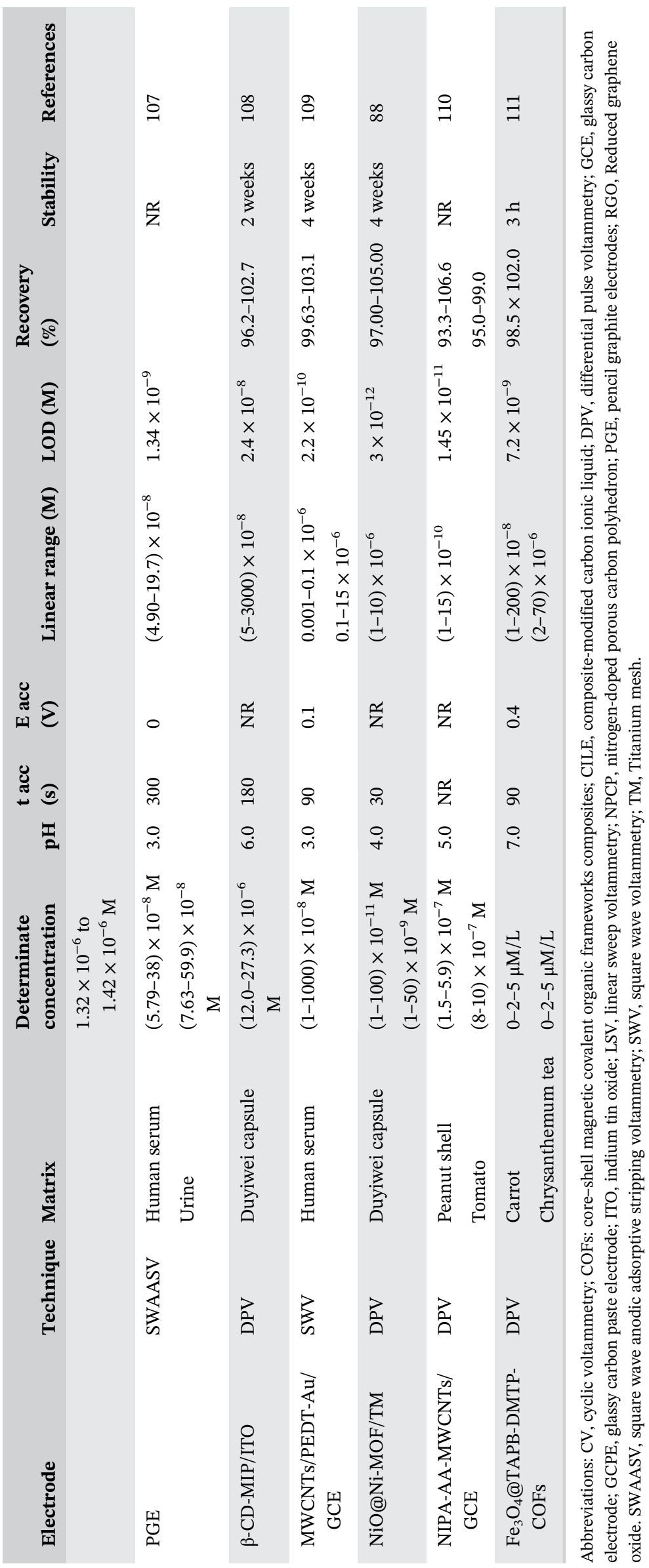


LOD value of $1.27 \times 10^{-9} \mathrm{~g} / \mathrm{ml}$. The work is carried out with samples extracted from honeysuckle with petroleum ether and then redissolved in buffer solution of Borax$\mathrm{HCl}$ at $\mathrm{pH} 6.00$.

In the same line, the article published by the group of $\mathrm{Lu}$ reported the synthesis of glutathione (GSH)-capped Mn-doped CdTe quantum dots, which are used as fluorescence probes and applied to the luteolin determination. ${ }^{113}$ Here, the flavonoid, acts one more time as a quencher of the fluorescence of quantum dots, and the fluorescence quenching is closely proportional to the amount of the flavonoid. Related to this article, it is important to highlight the wide linear range achieved $\left(6-138 \times 10^{-6} \mathrm{M}\right)$. The work is carried out by working with phosphate buffer solution at $\mathrm{pH}$ 9, reaching a LOD value of $6.1 \times 10^{-8} \mathrm{M}$. To evidence the developed method, the authors use the synthetic matrix of the commercial Duyiwei capsules, and they have been able to find a luteolin concentration values between 18.05 and $28.38 \times 10^{-6} \mathrm{M}$.

Although very good analytical parameters are achieved in both works, it is necessary to mention that they only quantify luteolin as a unique analyte in a real sample (i.e., honeysuckle or Duyiwei capsules), which compared to most of the mentioned techniques, can be taken as a disadvantage (only the presence of numerous interferents was studied).

On the other hand, Li et al. ${ }^{114}$ developed a novel fluorescent nanosensor that could be successfully applied to efficient detection of cis-diol-containing three flavonoids, including luteolin, in onion skin and human urine samples. With that purpose, novel boronate affinity imprinted quantum dots (BA-CdTe@MIPs QDs) were used to develop a selective and sensitive fluorescent nanosensor based on controllable oriented surface imprinting approach. The BA-CdTe@MIPs QDs exhibited linear decrease in fluorescence intensity with the increase of concentration of flavonoid in the $0.05-25 \mu \mathrm{M}$ concentration range. LOD was evaluated to be $0.02 \mu \mathrm{M}$. The recoveries for the spiked onion skin and urine samples were evaluated to be $83.50 \%-104.00 \%$ and $86.67 \%-105.00 \%$, respectively.

Another little-known technique in the determination of luteolin is electrophoresis. Briefly, this technique consists on the differential migration of molecules relative to a fluid under the influence of a spatially uniform electric field.

Regarding that, Chem and Xing reported the application of micellar electrokinetic capillary chromatography for the separation and determination luteolin and others five compounds in peanut shells ethanolic extract working with borate buffer at $\mathrm{pH} 9.24$. $^{115}$ They obtained really good analytical values like an extremely low LOD of $4 \times 10^{-7} \mathrm{~g} / \mathrm{ml}\left(\approx 1.4 \times 10^{-9} \mathrm{M}\right)$, a wide linear range,
$0.002-2 \times 10^{-3} \mathrm{~g} / \mathrm{ml}\left(\approx 7 \times 10^{-9}\right.$ to $\left.7 \times 10^{-6} \mathrm{M}\right)$ and a high reproducibly, with $0.097 \%$ RSD. Finally, working with the extract of the real sample, in this case peanut shells, they found a luteolin concentration of $6.314 \times 10^{-3} \mathrm{~g} / \mathrm{ml}$ $\left(\approx 2.2 \times 10^{-5} \mathrm{M}\right)$.

For their part, the group of Lunte and co-workers, reported a capillary electrophoretic method for determination of eight polyphenolic compounds in three different red wine samples, included among them, luteolin. In agreement with the authors, we would like to underline the speed of the proposed method, that in comparison with the current methods is truly fast. The eight determinations, including the sample pretreatment, were performed in about 15 min. ${ }^{116}$

Although the analytical parameters are not surprising, it is clear that it can be an excellent method to use routinely with these types of samples. This can be affirmed since in the work it can be observed that the variation of luteolin concentration in the three types of wines is very small and that, as we said previously, it is a very fast method.

A work that achieves very interesting analytical parameters is the one carried out by Maher and coworkers, determining luteolin (and apigenin) by capillary electrophoresis, with diode array detection, in thyme and parsley methanol extracts. ${ }^{117}$ Its LOD was $1.05 \mu \mathrm{g} / \mathrm{ml}$ $\left(\approx 3.7 \times 10^{-6} \mathrm{M}\right)$ with a lineal range from 3 to $800 \mu \mathrm{g} / \mathrm{ml}$ $\left(\approx 1.0 \times 10^{-5}\right.$ to $\left.2.8 \times 10^{-3} \mathrm{M}\right)$. But in comparison with the work of Lunte, this method applied to luteolin takes more time (only the elution time $27 \mathrm{~min}$ ).

Electrophoresis, in general, is a good option to the popular chromatography because of its simplicity, high resolution, low utilization of samples and chemicals and usually short analysis time.

\section{5 | CONCLUSIONS}

Over the last years, many different methods to quantify luteolin have been proposed. Chromatographic and electrochemical methods stand out for being the most used but are not the only ones. A shorter list of publications referring to the use fluorescence- and electrophoresisbased methods can be found. In this way, in this review current techniques for the determination of luteolin in real samples are shown, putting emphasis on the chromatographic and electroanalytical methods.

Many techniques provide a real possibility for the sample preparation prior to the analysis with sufficient specificity. However, there is not a standard available technique for the sample preparation and/or for the whole procedure. The liquid extraction is, in many cases, the first step in the preparation process of the sample. 
It is important to mention that, all through the article, we have highlighted and compared analytical developments that imply separation before determination (electrochemical sensors) with other methodologies, in which such separations are part of themselves, that is, they take place in the same equipment (cromatographies). The application of thin layer chromatography to identify different components from extracts is a classical method but still very used today. Through this technique, the chromatographic "fingerprint" of an extract can be obtained, which is very important for identification purposes, mainly limited to qualitative determinations.

To quantify luteolin in different matrices, it is highlighted that the possibility to connect multiple detection devices to HPLC has made this technique a valuable and essential tool for the separation of other flavonoids. Ultraviolet detection is currently technique used in liquid chromatography and, even, it is used with multiwavelengths or photo diode array. Thus, it is a conventional tool in studies associated with detection, quantification, and classification of flavonoids, included the luteolin. On the other hand, the development of liquid chromatography coupled to mass spectroscopy has extended the field of application of mass spectroscopy, allowing the analysis and identification of compounds from new natural products.

For high-throughput analysis, the development of new techniques such as ultra-efficiency liquid chromatography and UHPLC has emerged as an alternative to the traditional HPLC technique in the last years.

The relevance of UPLC technology mainly focuses on the improvement of the analytical parameters at expense of working with a lower number of analytes, while UHPLC, coupled to MS/MS detection, has the ability to analyze several analytes.

The results previously discussed clearly demonstrate that electroanalytical techniques are powerful tools to study compounds of interest to human and animal health, among them luteolin. The main advantage of electrochemical techniques over others such as chromatography, spectrophotometry, and so on is that they require less expensive equipment, less solvent use, they are quicker and show, in some cases, a greater sensitivity. Furthermore, voltammetric techniques also offer the possibility to developing electrochemical detectors for coupling to flow systems when becomes necessary to implement a pre-separation step in complex samples in the presence of several analytes.

Critical assessment of the potential of new analytical methods for the determination, qualitative and quantitative, of luteolin is crucial in analytical chemistry regardless of the specificity of the method. Usually, validation criteria are used for this purpose, including parameters such as precision, accuracy, sensitivity, recovery, and so on. This approach has the disadvantage that it is difficult to express the analytical potential of a methodology using one unified measure, which would cover all validation criteria and allow easy overall assessment. Due to this, conducting a comprehensive assessment of an analytical method covering all the mentioned attributes is extremely hard without special tools dedicated to this purpose.

Taking into account that luteolin is found in nature and in most laboratory determinations in relatively high concentrations, it is worth mentioning that LOD is no longer the most important analytical parameter. Thus, parameters such as the linear range became much more interesting, making the proposed method practical in everyday use.

In summary, we venture to say further developments may be expected with regards miniaturization, that is, the coupling of micro- and/or nano technologies, analytical instruments that they should facilitate the analysis of minute samples, and help to create better operating conditions for detection of luteolin in real samples still unknown. Besides hoping that with the instruments that generate higher-order data and the in-depth study of chemometrics, chemical multiway calibration will definitely start to play an important role in qualitative and quantitative analysis, allowing analytes to be determined even in the presence of unexpected interferences.

\section{ACKNOWLEDGMENTS}

Alvaro Y. Tesio and Sebastian N. Robledo are CONICET Research Fellows and both thank CONICET. Alvaro Y. Tesio especially thanks the Universidad Nacional de Jujuy. Sebastian N. Robledob thanks the Financial support from Agencia Nacional de Promoción Científica y Tecnológica FONCYT (00975 - 2018) (01580 - 2018), and Secretaría de Ciencia y Técnica, Universidad Nacional de Rio Cuarto (SECyT/UNRC, PPI 2020, Res. 083/20).

\section{DATA AVAILABILITY STATEMENT}

Data sharing is not applicable to this article as no new data were created or analyzed in this study.

\section{ORCID}

Alvaro Y. Tesio (1) https://orcid.org/0000-0001-9004-5947

\section{REFERENCES}

1. Di Carlo G, Mascolo N, Izzo AA, Capasso F. Flavonoids: old and new aspects of a class of natural therapeutic drugs. Life Sci. 1999;65:337-53.

2. Pokorny J, Yanishlieva N, Gordon M. Antioxidantes de los alimentos. Aplicaciones prácticas. Zaragoza, Spain: Acribia S. A; 2001. 
3. López-Lázaro M. Distribution and biological activities of the flavonoid luteolin. Mini-Rev Med Chem. 2009;9:31-59.

4. Sánchez de Rojas VR, Somoza B, Ortega T, Villar AM. Different mechanisms involved in the vasorelaxant effect of flavonoids isolated from satureja obovate. Planta Med. 1996;62: 554-6.

5. Middleton E, Kandaswami C. Effects of flavonoids on immune and inflammatory cell functions. Biochem Pharmacol. 1992;43:1167-79.

6. Cooks NC, Samman S. Flavonoids: chemistry, metabolism, cardioprotective effects, and dietary sources. J Nutr Biochem. 1996;7:66-76.

7. Fernandez MT, Mira ML, Florêncio MH, Jennings KR. Iron and copper chelation by flavonoids: an electrospray mass spectrometry study. J Inorg Biochem. 2002;92:105-11.

8. Park YJ, Kim HJ, Lee SJ, Choi HY, Jin C, Lee YS. A new chromone, 11-hydroxy-sec-O-glucosylhamaudol from Ostericum koreanum. Chem Pharm Bull. 2007;55:1065-6.

9. Kazuki K, Mari U, Hiroaki Y, Takashi H. Bioavailable flavonoids to suppress the formation of 8-OHdG in HepG2 cells. Arch Biochem Biophys. 2006;455:197-203.

10. Kempuraj D, Thangavel R, Kempuraj D, Ahmed M, Selvakumar G, Raikwar S, et al. Neuroprotective effects of flavone luteolin in neuroinflammation and neurotrauma. Biofactors. 2020;46:1-8.

11. Russo M, Moccia S, Spagnuolo C, Tedesco I, Russo GL. Roles of flavonoids against coronavirus infection. Chem Biol Interact. 2020;328:109211.

12. Huang Y-F, Bai C, He F, Xie Y, Zhou H. Review on the potential action mechanisms of Chinese medicines in treating Coronavirus Disease 2019 (COVID-19). Pharmacol Res. 2020;158:104939.

13. Solnier J, Fladerer JP. Flavonoids: a complementary approach to conventional therapy of COVID-19? Phytochem Rev. https://doi.org/10.1007/s11101-020-09720-6.

14. Theoharides TC. COVID-19, pulmonary mast cells, cytokine storms and beneficial actions of luteolin. BioFactors. 2020;46: 306-8.

15. Rasheed D, Serag A, Abdel Shakour Z, Farag M. Novel trends and applications of multidimensional chromatography in the analysis of food, cosmetics and medicine bearing essential oils. Talanta. 2021;223:121710-22.

16. Nowak PM, Kościelniak P, Tobiszewski M, BallesterCaudet A, Campíns-Falcó P. Overview of the three multicriteria approaches applied to a global assessment of analytical methods. TRAC. 2020;133:116065.

17. Olivieri A, Escandar G. Analytical chemistry assisted by multi-way calibration: a contribution to green chemistry. Talanta. 2019;204:700-12.

18. Tonello N, Moressi M, Robledo S, D'Eramo F, Marioli J. Square wave voltammetry with multivariate calibration tools for determination of eugenol, carvacrol and thymol in honey. Talanta. 2016;158:306-14.

19. Fernández H, Arévalo F, Granero A, Robledo S, Nieto C, Riberi I, et al. Electrochemical biosensors for the determination of toxic substances related to food safety developed in South America: mycotoxins and herbicides. Chemosensors. 2017;5:23.

20. Pierini G, Maccio S, Robledo S, García-Miranda Ferrari A, Banks C, Fernández H, et al. Screen-printed electrochemical- based sensor for taxifolin determination in edible peanut oils. Microchem J. 2020;159:105442.

21. Tesio AY, Robledo SN, Ceballos CD, Zon MA, Fernández H. Electrochemical ultra-micro sensors for the determination of synthetic and natural antioxidants in edible vegetable oils. Sen Actuat B-Chem. 2014;192:467-73.

22. Tesio AY, Granero AM, Fernández H, Zon MA. Characterization of the surface redox process of adsorbed morin at glassycarbon electrodes. Electrochim Acta. 2011;56:2321-7.

23. Tesio AY, Robledo SN, Fernández H, Zon MA. Electrochemical oxidation of butein at glassy carbon electrodes. Bioelectrochemistry. 2013;91:62-9.

24. Tesio AY, Granero AM, Vettorazzi NR, Ferreyra NF, Rivas GA, Fernández H, et al. Development of an electrochemical sensor for the determination of the flavonoid luteolin in peanut hull samples. Microchem J. 2014;115: $100-5$.

25. Tesio AY, Robledo SN, Granero AM, Fernández H, Zon MA. Simultaneous electroanalytical determination of luteolin and rutin using artificial neural networks. Sens Actuat B-Chem. 2014;203:655-62.

26. Tesio AY, Robledo SN, Granero AM, Fernández H, Zon MA. In: Dwight AJ, editor. Electroanalytical determinations of luteolin in luteolin natural occurrences, therapeutic applications and health effects. New York: Nova Science Publishers, Inc; 2015. p. 73-100.

27. Marston A. Thin-layer chromatography with biological detection in phytochemistry. J Chromatogr A. 2011;1218(19): 2676-83.

28. Patel NG, Patel KG, Patel KV, Gandhi TR. Validated HPTLC method for quantification of luteolin and apigenin in premna mucronata Roxb., Verbenaceae. Adv Pharm Sci. 2015. https:// doi.org/10.1155/2015/682365.

29. Satpathy S, Patra A, Ahirwar B. Development and validation of a novel high-performance thin-layer chromatography method for the simultaneous determination of apigenin and luteolin in Hygrophila spinosa T. Anders J Planar Chromat. 2018;31:437-43.

30. Lan D, Liu J, Guo X, Zhu G, Tian S. Determining the contents of rupestonic acid, vitexicarpin, apigenin, and luteolin in Artemisia rupestris L. in different growth stages by thin-layer chromatographic scanning. J Planar Chromat. 2018;31(3):190-6.

31. Kroslakova I, Pedrussio S, Wolfram E. Direct coupling of HPTLC with MALDI-TOF MS for qualitative detection of flavonoids on phytochemical fingerprints. Phytochem Anal. 2016;27:222-8.

32. Hawrył MA, Hawrył A, Świeboda R, Niemiec M, Waksmundzka-Hajnos M. Thin-layer chromatography and chemometric analysis in the fingerprinting of selected Scutellaria species. J Planar Chromat. 2016;29(4):256-63.

33. Wu R, Ma F, Zhang L, Li P, Li G, Zhang Q, et al. Simultaneous determination of phenolic compounds in sesame oil using LC-MS/MS combined with magnetic carboxylated multi-walled carbon nanotubes. Food Chem. 2016;204: 334-42.

34. Tomczyk M, Ceylan O, Locatelli M, Tartaglia A, Ferrone V, Sarikurkcu C. Ziziphora taurica subsp. taurica: analytical characterization and biological activities. Biomolecules. 2019; 9:367-76. 
35. Han L, Liu E, Kojo A, Zhao J, Li W, Zhang Y, et al. Qualitative and quantitative analysis of Eclipta prostrata L. by LC/MS. Sci World J. 2015;2015:1-15. https://doi.org/10.1155/ 2015/980890.

36. Monago-Maraña $\mathrm{O}$, Muñoz de la Peña A, Galeano-Díaz T. Isocratic LC-DAD-FLD method for the determination of flavonoids in paprika samples by using a rapid resolution column and post-column $\mathrm{pH}$ change. Talanta. 2016;152:15-22.

37. Qiu J, Chen X, Li Z, Wang S, Wu X, Li Y, et al. LC-MS/MS method for the simultaneous quantification of 11 compounds of Ginkgo biloba extract in lysates of mesangial cell cultured by high glucose. J Chromatogr B. 2015;997:122-8.

38. Desta KT, Kim GS, Abd El-Aty AM, Raha S, Kim MB, Jeong $\mathrm{JH}$, et al. Flavone polyphenols dominate in Thymus schimperi Ronniger: LC-ESI-MS/MS characterization and study of anti-proliferative effects of plant extract on AGS and HepG2 cancer cells. J Chromatogr B. 2017;1053:1-8.

39. Guo Y, Liu H, Ding L, Oppong M, Pan G, Qiu F. LC-MS/MS method for simultaneous determination of flavonoids and physalins in rat plasma: application to pharmacokinetic study after oral administration of Physalis alkekengi var. franchetii (Chinese lantern) extract. Biomed Chromatogr. 2017;31. https://doi.org/10.1002/bmc.3970.

40. Moreno-González R, Juan ME, Planas JM. Table olive polyphenols: a simultaneous determination by liquid chromatography-mass spectrometry. J Chromatogr A. 2020; 1609:460434. https://doi.org/10.1016/j.chroma.2019.460434.

41. Riyazuddin M, Husain A, Verma S, Katekar R, Garg R, Kumar S, et al. Simultaneous quantification of five biomarkers in ethanolic extract of Cassia occidentalis Linn. Stem using liquid chromatography tandem mass spectrometry: application to its pharmacokinetic studies. RSC Adv. 2020;10: 4579-88.

42. Szultka M, Buszewski B, Papaj K, Szeja W, Rusin A. Determination of flavonoids and their metabolites by chromatographic techniques. TRAC. 2013;47:47-67.

43. de Villiers A, Venter P, Pasch H. Recent advances and trends in the liquid-chromatography-mass spectrometry analysis of flavonoids. J Chromatogr A. 2016;1430:16-78.

44. de Rijke E, Out P, WMA N, Ariese F, Gooijer C, UAT B. Analytical separation and detection methods for flavonoids. J Chromatogr A. 2006;1112:31-63.

45. Ganzera M, Sturm S. Recent advances on HPLC/MS in medicinal plant analysis-An update covering 2011-2016. J Pharmaceut Biomed. 2018;147:211-33.

46. Kumar BR. Application of HPLC and ESI-MS techniques in the analysis of phenolic acids and flavonoids from green leafy vegetables (GLVs). J Pharm Anal. 2017;7:349-64.

47. Ma N-H, Guo J, Chen XS-H, Yuan X-R, Zhang T, Ding Y. Antioxidant and compositional HPLC analysis of three common bamboo leaves. Molecules. 2020;25:409-23.

48. Yin L, Zheng X, Wang G, Wang W. Microwave irradiation followed by zinc oxide based dispersive solid-phase extraction coupled with HPLC for simultaneous extraction and determination of flavonoids in Veronicastrum latifolium (Hemsl.) Yamazaki. Anal Bioanal. 2019;411(5):1029-40.

49. Zhang X-X, Shi Q-Q, Ji D, Niu L-X, Zhang Y-L. Determination of the phenolic content, profile, and antioxidant activity of seeds from nine tree peony (Paeonia section Moutan DC.) species native to China. Food Res Int. 2017;97:141-8.

50. Du Y, Han J, Sun S, Li Z, Yang F, Dong L, et al. Simultaneous determination of 11 components in yinzhihuang preparations and their constituent herbs by high-performance liquid chromatography with diode array detector. J Chromatogr Sci. 2016;54(4):625-32.

51. Sarikahya NB, Goren AC, Kirmizigul S. Simultaneous determination of several flavonoids and phenolic compounds in nineteen different Cephalaria species by HPLC-MS/MS J Pharmaceut Biomed. 2019;173:120-5.

52. Yan W, Han Q, Guo P, Wang C, Zhang Z. Simultaneous detection of flavonoids, phenolic acids and alkaloids in abri herba and abri mollis herba using liquid chromatography tandem mass spectrometry. Phytochem Anal. 2016;27:50-6.

53. Zhang X, Liang C, Li C, Bu M, Bu L, Xiao Y, et al. Quantitative study of main compounds in Commelina communis Linn. by UHPLC-Q-TOF-MS-MS and HPLC-ESI-MS-MS. J Chromatogr Sci. 2018;56(7):582-94.

54. Yang W, He S, Xiao N, Qiao Y, Sui H, Liang L, et al. Simultaneous determination of 15 flavonoids in Scutellaria barbataHedyotis diffusa Herb Pair by HPLC Q-TOF MS. J AOAC Int. 2019;102(1):75-80.

55. Shui S, Liu W, Liu C, Yan L, Hao G, Zhang Y, et al. Discrimination of cultivars and determination of Luteolin content of Chrysanthemum morifolium Ramat. using multispectral imaging system. Anal Methods. 2018;10:1640-6.

56. Muti HY, Olimat S. HPLC method of analysis for determination and standardization of luteolin and vanillic acid in dry extract of paronychia argentea Lam. Orient J Chem. 2018;34: 2721-7.

57. Dong X, Lan W, Yin X, Yang C, Wang W, Ni J. Simultaneous determination and pharmacokinetic study of quercetin, luteolin, and apigenin in rat plasma after oral administration of Matricaria chamomilla L extract by HPLC-UV. Evid-Based Compl Alt. 2017;2017:1-7. https://doi.org/10.1155/2017/ 8370584.

58. Liu Y, Hu J, Li Y, Wang Z-L, Li X-S. Metal-organic framework MIL-101 as sorbent based on double-pumps controlled on-line solid-phase extraction coupled with high-performance liquid chromatography for the determination of flavonoids in environmental water samples. Electrophoresis. 2016;37:2478-86.

59. Dramou P, Itatahine A, Fizir M, Mehdi YA, Kutoka PT, HE H. Preparation of novel molecularly imprinted magnetic graphene oxide and their application for quercetin determination. J Chromatogr B 2019. 1124;273:283.

60. Bardakci H, Acar ET, Kırmızıbekmez H. Simultaneous quantification of six flavonoids in four Scutellaria taxa by HPLCDAD method. Rev Bras Farmacogn. 2019;29:17-23.

61. Tian S, Liu W, Liu F, Zhang X, Upur H. Development and validation of an high-performance liquid chromatography-diode array detector method for the simultaneous determination of six phenolic compounds in abnormal savda munziq decoction. Pharmacogn Mag. 2015;17:157-62.

62. Mai J, Liang J, Liu XF, Tan LP, Xu H, Li YH, et al. Simultaneous determination of 5 components in the leaves of Dimocarpus longan by quantitative analysis of multicomponents by single marker (QAMS) based on UPLC and HPLC. 
J Anal Methods Chem. 2020;2020:1-9. https://doi.org/10. 1155/2020/3950609.

63. Caprioli G, Boarelli MC, Ricciutelli M, Sagratini G, Fiorini D. Micro-scaled quantitative method to analyze olive oil polyphenols. Food Anal Methods. 2019;12:1133-9.

64. Wang N, Liao Y, Wang J, Tang S, Shao S. Solid-phase extraction using bis(indolyl)methane-modified silica reinforced with multiwalled carbon nanotubes for the simultaneous determination of flavonoids and aromatic organic acid preservatives. J Sep Sci. 2015;38:4111-8.

65. Corell L, Armenta S, Esteve-Turrillas FA, de la Guardia M. Flavonoid determination in onion, chili and leek by hard cap espresso extraction and liquid chromatography with diode array detection. Microchem J. 2018;140:74-9.

66. Liu C, Liao Y, Huang X, Chen L, Li Y. Fabrication of N,Ndimethyldodecylamine functionalized magnetic adsorbent for efficient enrichment of flavonoids. Talanta. 2019;194:771-7.

67. Wu J, Xiao D, Zhao H, He H, Peng J, Wang C, et al. A nanocomposite consisting of graphene oxide and $\mathrm{Fe} 3 \mathrm{O} 4$ magnetic nanoparticles for the extraction of flavonoids from tea, wine and urine samples. Microchim Acta. 2015;182:2299-306.

68. Cen M, Ruan J, Huang L, Zhang Z, Yu N, Zhang Y, et al. Simultaneous determination of thirteen flavonoids fromXiaobuxinTang extract using high-performance liquidchromatography coupled with electrospray ionization massspectrometry. J Pharm Biomed. 2015;115:214-24.

69. Song G, Zhou L, Sheng N, Zhang X, Xu Y, Zhang L, et al. Simultaneous quantification of 16 bioactive constituents in common cnidium fruit by liquid chromatography-electrospray ionizationmass spectrometry. J Pharm Biomed. 2015;107:304-10.

70. Shen J, Jia Q, Huang X, Yao G, Ma W, Zhang H, et al. Development of a HPLC-MS/MS method to determine the 13 elements of semen cuscutae and application to a pharmacokinetic study in rats. Evid Based Complement Alternat Med. 2019;2019:1-11. https://doi.org/10.1155/2019/6518528.

71. Lee J, Rodriguez JP, Quilantang NG, Lee M-H, Cho E-J, Jacinto SD, et al. Determination of flavonoids from Perilla frutescens var. japonica seeds and their inhibitory effect on aldose reductase. Appl Biol Chem. 2017;60:155-62.

72. Trabelsi A, Kaibi MA, Abbassi A, Horchani A, ChekirGhedira L, Ghedira K. Phytochemical Study and Antibacterial and Antibiotic Modulation Activity of Punica granatum (Pomegranate) Leaves. Scientifica. 2020;2020:1-7. https://doi. org/10.1155/2020/8271203.

73. Fountain KJ. UPLC versus UHPLC: comparison of loading and peak Capacity for Small Molecule Drugs. Application note. Waters 2011 720003869EN IH-PDF.

74. Tian Y, Li Q, Zhou X, Pang Q, Xu Y. A UHPLC-MS/MS method for simultaneous determination of twelve constituents from Erigeron breviscapus extract in rat plasma: application to a pharmacokinetic study. J Chromatogr B. 2017;1046:1-12.

75. da Silva Silveira R, Camera Leal G, Ramos Dal Molin T, Faccin H, Assis Gobo L, Domingos da Silveira G, et al. Determination of phenolic and triterpenic compounds in Jatropha gossypiifolia L by Ultra-high performance liquid chromatographytandem mass spectrometric (UHPLC-MS/MS). Braz. J Pharm Sci. 2020;56:17262.

76. Alarcón-Flores MI, Romero-González R, Martínez Vidal JL, Garrido Frenich A. Multiclass determination of phenolic compounds in different varieties of tomato and lettuce by ultra high performance liquid chromatography coupled to tandem mass spectrometry. Int J Food Prop. 2016;19:494-507.

77. Hu K, Deng Z, Li S, Wu M, Liu W, Zhang S. SPE-UHPLC$\mathrm{DAD}$ method for the simultaneous determination of three flavonoids in grape juice by using Bis(tetraoxacalix[2] arene[2]triazine)-modified silica as sorbent. Food Anal Methods. 2017; 10:3434-42.

78. Hwang SH, Paek JH, Lim SS. Simultaneous ultra performance liquid chromatography determination and antioxidant activity of linarin, luteolin, chlorogenic acid and apigenin in different parts of compositae species. Molecules. 2016;21:1609-22.

79. Wang Y, Li S, Han D, Meng K, Wang M, Zhao C. Simultaneous determination of rutin, luteolin, quercetin, and betulinic acid in the extract of disporopsis pernyi (Hua) Diels by UPLC. J Anal Methods Chem. 2015;2015:1-5. https://doi.org/10.1155/2015/130873.

80. Wang Y, Wang P, Xie J, Yin Z, Lin X, Zhao Y, et al. Pharmacokinetic comparisons of different combinations of Yigan Jiangzhi formula in rrats: simultaneous determination of fourteen components by UPLC-MS/MS. J Anal Methods Chem. 2020;2020:1-16. https://doi.org/10.1155/2020/9353975.

81. Wei B-B, Chen Z-X, Liu M-Y, Wei M-J. Development of a UPLC-MS/MS method for simultaneous determination of six flavonoids in rat plasma after administration of maydis stigma extract and its application to a comparative pharmacokinetic study in normal and diabetic rats. Molecules. 2017;22:1267-80.

82. Wang T, Xiao J, Hou H, Li P, Yuan Z, Xu H, et al. Development of an ultra-fast liquid chromatography-tandem mass spectrometry method for simultaneous determination of seven flavonoids in rat plasma: Application to a comparative harmacokinetic investigation of Ginkgo biloba extract and single pure ginkgo flavonoids after oral administration. J Chromatogr B. 2017;1060:173-81.

83. Zhou W, Shan J, Ju W, Wang S, Meng M, Cai B, et al. Simultaneous determination of twenty-six components of Flos Lonicerae Japonicae - Fructus Forsythiae herb couple using UPLC-ESI-MS/MS, application to its preparations. Anal Methods. 2015;7:1425-37.

84. Yang H, Shi H, Zhang Q, Liu Y, Wan C, Zhang L. Simultaneous determination of five components in Aster tataricus by ultra performance liquid chromatography-tandem mass spectrometry. J Chromatogr Sci. 2016;54:500-6.

85. Viera GS, Marques ASF, Machado MTC, Silva VM, Hubinger MD. Determination of anthocyanins and non-anthocyanin polyphenols by ultra performance liquid chromatography/electrospray ionization mass spectrometry (UPLC/ESI-MS) in jussara (Euterpe edulis) extracts. J Food Sci Technol. 2017;54:2135-44.

86. Liu G, Qiao S, Liu T, Yu H, Wang W, Zhou Y, et al. Simultaneous determination of 18 chemical constituents in traditional chinese medicine of antitussive by UPLC-MS-MS. J Chromatogr Sci. 2016;54:1540-52.

87. Fu L, Liu Z, Huang Y, Lai G, Zhang H, Su W, et al. Square wave voltammetric quantitative determination of flavonoid luteolin in peanut hulls and Perilla based on Au NPs loaded boron nitride nanosheets. J Electroanal Chem. 2018;817:128-33.

88. Wu T, Liu Z, Guo Y, Dong C. Electrochemical sensor for facile detection of trace luteolin based on thio- $\beta$-cyclodextrin functionalized graphene/gold nanoparticles hybrids. J Electroanal Chem. 2015;759:137-43. 
89. Gao F, Tu G, Ma X, Xie Y, Zou J, Huang X, et al. NiO@NiMOF nanoarrays modified Ti mesh as ultrasensitive electrochemical sensing platform for luteolin detection. Talanta. 2020; 215:120891. https://doi.org/10.1016/j.talanta.2020.120891.

90. Huang Q, Lin $\mathrm{X}$, Lin $\mathrm{C}$, Zhang $\mathrm{Y}$, Zhang $\mathrm{H}$, Hu S, et al. Ultrasensitive-electrochemical sensor for the detection of luteolin in chrysanthemums and peanut shells using an $\mathrm{Au} / \mathrm{Pd} /$ reduced graphene oxide nanofilm. Anal Methods. 2016;8:6347-52.

91. Chamizo-González F, Monago-Maraña O, Galeano-Díaz T. Determination of quercetin and luteolin in paprika samples by voltammetry and partial least squares calibration. Electroanal. 2017;29:1-10.

92. Tesio AY, Robledo SN, Granero AM, Fernandez H, Zon MA. Simultaneous electroanalytical determination of luteolin and rutinusing artificial neural networks. Sens Actuators B. 2014; 203:655-62.

93. Fu L, Zheng Y, Wang A. Poly (diallyldimethylammonium chloride) functionalized reduced graphene oxide based electrochemical sensing platform for luteolin determination. Int $\mathrm{J}$ Electrochem Sci. 2015;10:3518-29.

94. Ibrahim H, Temerk Y. Novel sensor for sensitive electrochemical determination of luteolin based on In2O3 nanoparticles modified glassy carbon paste electrode. Sensor Actuat BChem. 2015;206:744-52.

95. Liao Y, Wang N, Ni Y, Xu J, Shao S. Electrochemical sensor based on Nbim/CNT composite for selective determination of luteolin in the flavonoid. J Electroanal Chem. 2015;754:94-9.

96. Ran X, Yang L, Zhao G, Ye H, Zhang Y, Fan S, et al. Simultaneous determination of two flavonoids based on disulfide linked b-cyclodextrin dimer and Pd cluster functionalized graphene-modified electrode. RSC Adv. 2015;5:60775-85.

97. Tang J, Jin B. Electrochemical determination of luteolin in chrysanthemum using multi-walled carbon nanotubes-ionic liquid composite electrode. Anal Methods. 2015;7:894-900.

98. Gao F, Chen X, Tanaka H, Nishitani A, Wang Q. Alkaline phosphatase mediated synthesis of carbon nanotube-hydroxyapatite nanocomposite and its application for electrochemical determination of luteolin. Adv Powder Technol. 2016;27:921-8.

99. Tang J, Jin B. Poly(crystal violet) -multi-walled carbon nanotubes modified electrode for electroanalytical determination of luteolin. J Electroanal Chem. 2016;780:46-52.

100. Zuo Y, Xu J, Zhang K, Duan X, Lu L, Wu L, et al. Application of poly(3,4-thylenedioxythiophene)/manganese dioxide composite-modified electrode for sensitive electrochemical detection of luteolin. Int J Electrochem Sci. 2016;11:3776-85.

101. Xu B, Zhang B, Yang L, Zhao F, Zeng B. Electrochemical determination of luteolin using molecularly imprinted poly-carbazole on MoS2/graphene-carbon nanotubes nanocomposite modified electrode. Electrochim Acta. 2017;258:1413-20.

102. Cao M, Yin X, Bo X, Guo L. High-performance electrocatalyst based on metal-organic framework/macroporous carbon composite for efficient detection of luteolin. J Electroanal Chem. 2018;824:153-60.

103. Feng X, Yin X, Bo X, Guo L. An ultrasensitive luteolin sensor based on MOFs derived CuCo coated nitrogen-doped porous carbon polyhedron. Sens Actuators B-Chem. 2019;281:730-8.

104. Liu H, Hassan M, Bo X, Guo L. Fumarate-based metal-organic framework/mesoporous carbon as a novel electrochemical sensor for the detection of gallic acid and luteolin.
J Electroanal Chem. 2019;849:113378. https://doi.org/10.1016/ j.jelechem.2019.113378.

105. Liu J, Cheng H, Xie H, Luo G, Niu Y, Zhang S, et al. Platinum nanoparticles decorating a biomass porous carbon nanocomposite-modified electrode for the electrocatalytic sensing of luteolin and application. RSC Adv. 2019;9:33607-16.

106. Tang J, Huang R, Zheng S, Jiang S, Yu H, Li Z, et al. A sensitive and selective electrochemical sensor based on graphene quantum dots/gold nanoparticles nanocomposite modified electrode for the determination of luteolin in peanut hulls. Microchem J. 2019;145:899-907.

107. Ibrahim H, Temerk Y, Schuhmann W. Simultaneous anodic adsorptive stripping voltammetric determination of luteolin and 3-hydroxyflavone in biological fluids using renewable pencil graphite electrodes. Electroanalysis. 2019;31:1095-103.

108. Wei M, Geng X, Liu Y, Long H, Du J. A novel electrochemical sensor based on electropolymerized molecularly imprinted polymer for determination of luteolin. J Electroanal Chem. 2019;842:184-92.

109. Chen W, Zeng P, Ma C, Peng H, Yang J, Huang J, et al. Electrochemical sensor for sensitive detection of luteolin based on multiwalled carbon nanotubes/poly (3,4-ethylenedioxythiophene)-gold nanocomposites. New J Chem. 2020;44:1953-61.

110. Ma Y, Kong Y, Xu J, Deng Y, Lu M, Yu R, et al. Carboxyl hydrogel particle film as a local $\mathrm{pH}$ buffer for voltametric determination of luteolin and baicalein. Talanta. 2020;208: 120373.

111. Xie Y, Zhang T, Chen Y, Wang Y, Wang L. Fabrication of core-shell magnetic covalent organic frameworks composites and their application for highly sensitive detection of luteolin. Talanta. 2020;213:120843.

112. Huang W, Wang F, Zhu H. Determination of luteolin by fluorescence spectrometry. Adv Mater Res. 2014;941:994-7.

113. Li L, Yu L, Ding Y, Zhang Q, Lu Y. The synthesis of novel Mn-doped CdTe fluorescence probes and their application in the determination of luteolin. Anal Methods. 2015;7:3855-62.

114. Li D, Zhai S, Song R, Liu Z, Wang W. Determination of cisdiol-containing flavonoids in real samples using boronate affinity quantum dots coated with imprinted silica based on controllable oriented surface imprinting approach. Spectrochim Acta A Mol Biomol Spectrosc. 2020;227:117542-50.

115. Xing $X$, Chen H. Determination of the pharmaceutically active components in peanut shells by micellar electrokinetic capillary chromatography. Anal Lett. 2015;48:1089-98.

116. Şanli S, Şanli N, Ozkan SA, Lunte C. Development and validation of a green capillary electrophoretic method for determination of polyphenolic compounds in red wine samples. Chromatographia. 2016;79:1351-8.

117. Maher HM, Al-Zoman NZ, Al-Shehri MM, Al-Showiman H, Al-Taweel AM, Fawzy GA, et al. Determination of luteolin and apigenin in herbs by capillary electrophoresis with diode array detection. Instrum Sci Technol. 2015;43(6):611-25.

How to cite this article: Tesio AY, Robledo SN. Analytical determinations of luteolin. BioFactors. 2021;1-24. https://doi.org/10.1002/biof.1720 